\title{
Coupling global and regional circulation models in the coastal Gulf of Alaska
}

\author{
A.J. Hermann ${ }^{\text {a,* }}$, D.B. Haidvogel ${ }^{\text {b }}$, E.L. Dobbins ${ }^{\text {a, }}$, P.J. Stabeno ${ }^{\mathrm{c}}$ \\ a Joint Institute for the Study of Atmosphere and Ocean (JISAO), University of Washington, Seattle, WA 98195, USA \\ ${ }^{\mathrm{b}}$ Institute of Marine and Coastal Sciences, Rutgers University, New Brunswick, NJ 08901, USA \\ ${ }^{c}$ Pacific Marine Environmental Laboratory (PMEL), National Oceanic and Atmospheric Administration (NOAA), Seattle, WA \\ 98115, USA
}

\begin{abstract}
As part of the US GLOBEC NE Pacific program, we are simulating currents in the Coastal Gulf of Alaska (CGOA) to explore sources of interannual and interdecadal variability. To do so, we have developed a coupled modeling system composed of linked regional and global circulation models. The regional model, configured with 13-22 km resolution in the CGOA, is forced at the surface by observed heat fluxes and wind stresses, at the continental boundaries by observed runoff, and at the open ocean boundaries by a combination of tracer climatologies and sub-tidal velocity and tidal elevation provided by a global finite element model. In this communication, we describe the coupled system, including its present method of intermodel coupling, describe a series of multi-year model hindcasts, compare hindcast results with Eulerian and Lagrangian field data obtained in the CGOA in fall 1996, and assess the impact of global information (barotropic sub-tidal velocities and tidal elevations) on the regional model under the present coupling strategy. We find that the regional model produces appropriate current systems (Alaskan Stream, Alaska Coastal Current) and scalar fields, but with mesoscale variability (of SSH and velocities) at somewhat reduced strength relative to data, and with temperature gradients somewhat larger than those observed. Barotropic sub-tidal information from the global model penetrates the regional model interior, supplying additional mesoscale variability, and modifying regional velocity and scalar fields in both shallow and deep areas. Tidal information exerts a significant influence on sub-tidal scalar and velocity structure only in specific shallow areas, where the tides (and tidal mixing) are strongest. Pending the exploration of alternate coupling schemes, we infer from these results that on a time scale of months, purely barotropic information from outside the CGOA will have a modest impact on its mean regional circulation, but a potentially stronger impact on the statistics and details of mesoscale eddies. ( 2002 Published by Elsevier Science Ltd.
\end{abstract}

\section{Contents}

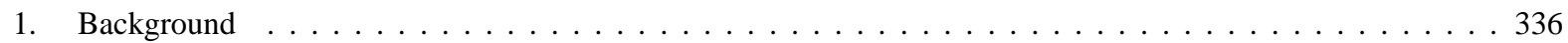

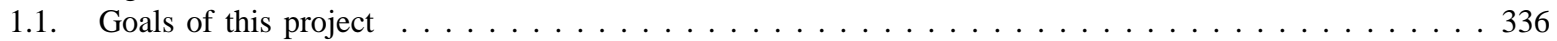

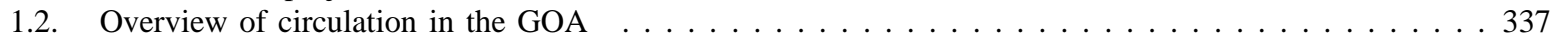

* Corresponding author.

E-mail address: hermann@pmel.noaa.gov (A.J. Hermann). 


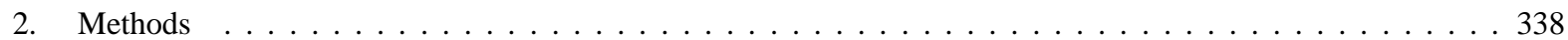

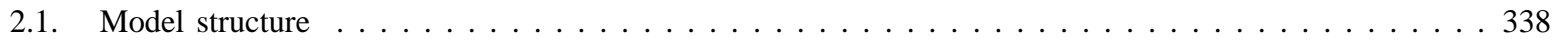

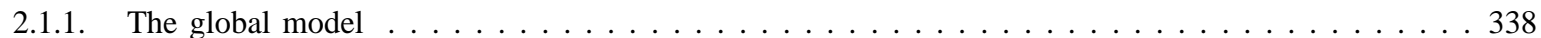

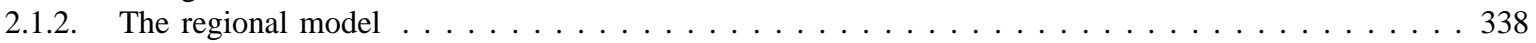

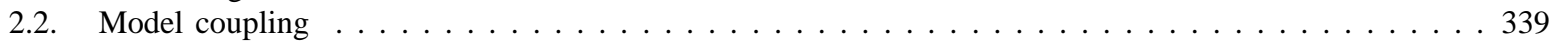

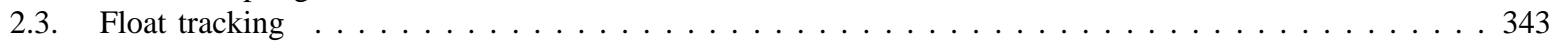

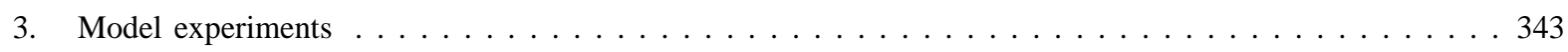

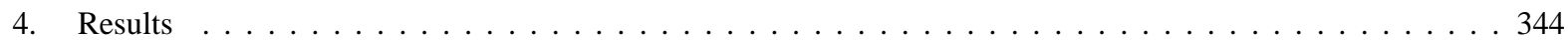

4.1. Global model results . . . . . . . . . . . . . . . . . . . . . . . . . . . . . . . . . . . . 344

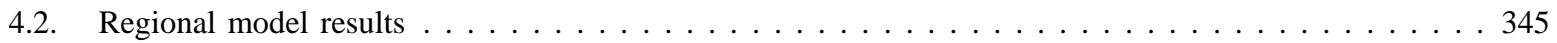

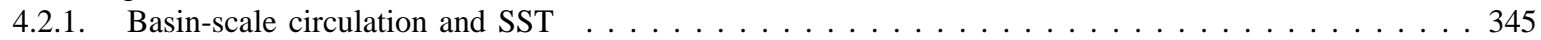

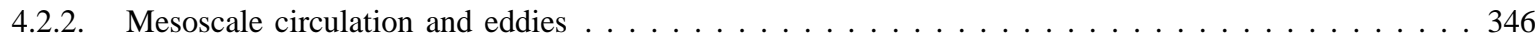

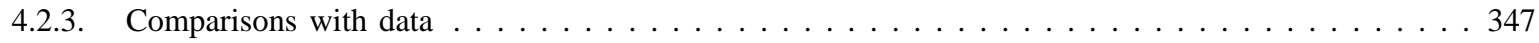

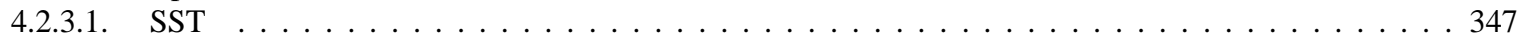

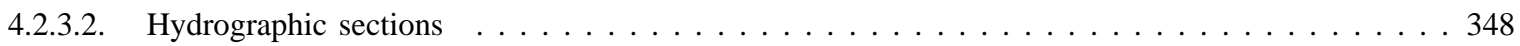

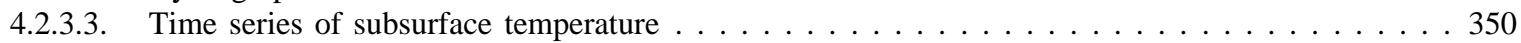

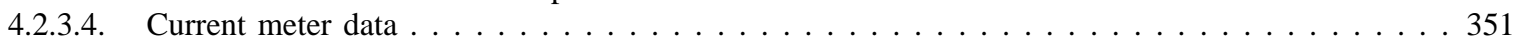

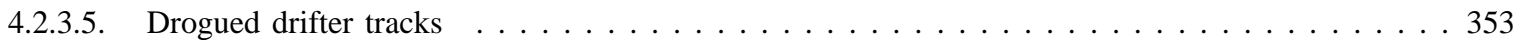

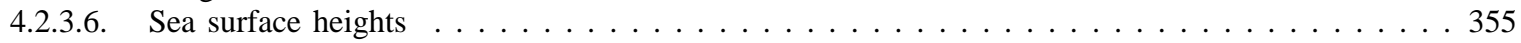

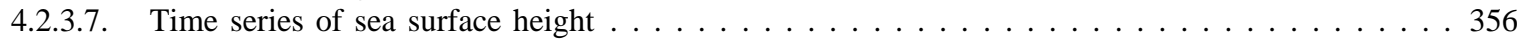

4.3. Sensitivity of the regional model to remote barotropic influence $\ldots \ldots \ldots \ldots \ldots \ldots \ldots \ldots$

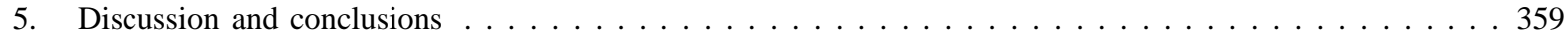

\section{Background}

\subsection{Goals of this project}

A core hypothesis of the US GLOBEC Northeast Pacific program is that interannual to interdecadal variability in the circulation and hydrography of the Gulf of Alaska drives changes in productivity of zooplankton in the coastal zone, with consequent effects on the feeding success of salmonids and other species in the Gulf (US GLOBEC, 1996). To help establish these linkages in the CGOA, we have been developing with our biological colleagues a set of linked circulation models, coupled with a lower trophic level Nutrient-Phytoplankton-Zooplankton (NPZ) biological model and an individual based model (IBM) of salmon. Specific issues to be addressed by this suite of models include the relative importance of surface Ekman flux, flows through submarine canyons, and mesoscale eddies on cross shelf exchange, and the subsequent impacts of that exchange on plankton and fish (both through resupply of nutrients and transport of the organisms themselves).

As part of this larger effort for GLOBEC, we have thus far developed both global and regional circulation models, bathymetry and forcing datasets for each, and a method for passing both tidal and sub-tidal information from the global to the regional model. Initial runs have yielded prominent spatial, seasonal, and interannual differences. Here, our goals are:

(a) to describe the coupled global/regional physical modeling system as it exists presently; 
(b) to assess the primary features of the physical circulation generated by those models for a specific time period and compare them with available data; and

(c) to assess the impact of remote barotropic information (tidal elevation and depth-averaged velocities) on the regional model behavior.

In light of these results, we consider possible improvements to the present coupling strategy.

\subsection{Overview of circulation in the $G O A$}

The Gulf of Alaska contains two major current systems: the Alaskan Current (AC)-Alaskan Stream (AS) and the Alaska Coastal Current (ACC) (Fig. 1). The AS is the intensified northern boundary of the AC; both are part of the subarctic gyre forced by cyclonic winds in the northeastern Pacific. Reed and Schumacher (1986) summarized knowledge of the AC-AS and ACC. The AS is constrained by a steep continental rise, which parallels the Aleutian Island chain. It is generally steady on seasonal time scales, but varies interannually (Reed, 1984; Musgrave, Weingartner, \& Royer, 1992; Lagerloef, 1995; Bhaskaran, Lagerloef, Born, Emery, \& Leben, 1993; Matthews, Johnson, \& O’Brien, 1992; Strub \& James, 2002a,b). The ACC is driven by a widely distributed coastal source of freshwater and downwelling favorable winds (Royer, 1981; Schumacher, Stabeno, \& Roach, 1990). Continuity of this current in the northern and western Gulf has been established (Stabeno, Reed, \& Schumacher, 1995). Significant bifurcation of the ACC occurs at several locations along the coast, with offshore-flowing branches joining the AS. The ACC is stronger in the western GOA (Reed, Schumacher, \& Wright, 1981); presumably because of both the stronger local downwelling and a larger volume of accumulated runoff. It has been suggested that the baroclinic structure of the eastern ACC is too weak to support baroclinic instability (Swaters \& Mysak, 1985), which is prevalent in parts of the western Gulf (Mysak, Muench, \& Schumacher, 1981).

The intermittently formed Sitka eddy, centered off Sitka, Alaska (Tabata, 1982), and meanders of the Alaskan Stream in the central and western Gulf (Musgrave et al., 1992; Reed \& Stabeno, 1993; Stabeno \&

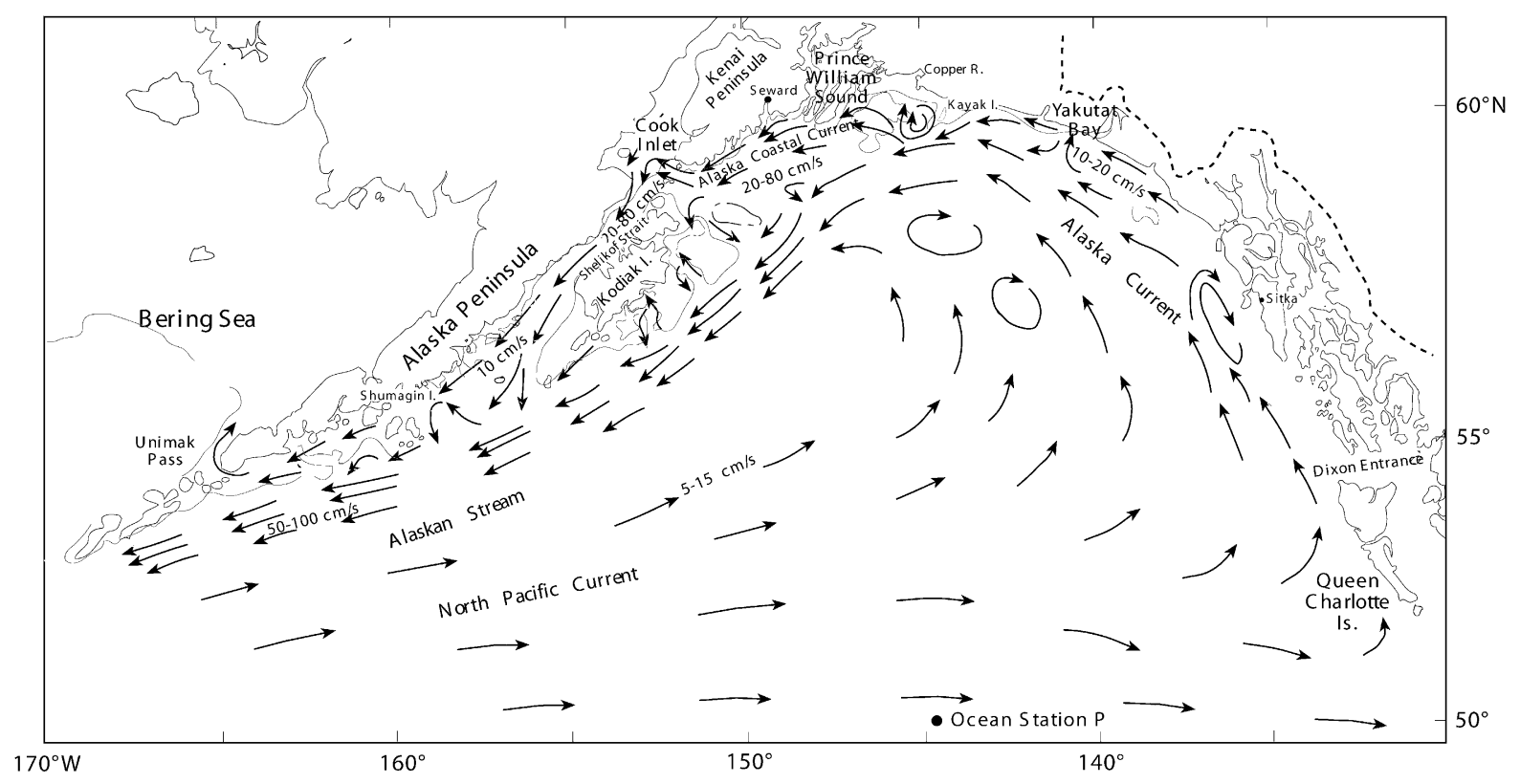

Fig. 1. Overview of circulation in the Gulf of Alaska. 
Reed, 1989; Thomson \& Gower, 1998) are prominent mesoscale features with scales of $\sim 200 \mathrm{~km}$. These large eddies typically drift at $<2 \mathrm{~cm} \mathrm{~s}^{-1}$, are predominantly anticyclonic, and are more commonly observed in spring (Crawford \& Whitney, 1999). Modeling studies have suggested that such eddies near the shelf break are intensified by ENSO warm events (Melsom, Meyers, Hurlburt, Metzger, \& O’Brien, 1999). The Sitka eddy has been reported to be topographically generated (Swaters \& Mysak, 1985), and to have average surface currents of $0.15 \mathrm{~m} \mathrm{~s}^{-1}$, with a maximum of $1.10 \mathrm{~m} \mathrm{~s}^{-1}$ as measured by drifters.

\section{Methods}

\subsection{Model structure}

To be useful in studying cross-shelf transport, a regional model of the CGOA must be sufficient to resolve baroclinic instabilities of the flow. Vertical resolution must also be sufficient to allow both the decoupling of flow from topography under stratified conditions and the development of appropriate shears when the flow is baroclinically unstable. The CGOA is a downwelling area with regions of significant tidal mixing, so the model must resolve surface and bottom boundary layers, which can meet in the shallow regions. As a method of investigating the interannual variations, the regional model should be informed at its boundaries with circulation and scalar fields appropriate to specific days and years. Here we briefly describe our global and regional models, which begin to achieve these intricate modeling objectives, and detail how a global model can be used to constrain the regional model simulations.

\subsubsection{The global model}

The large-scale context for our regional studies is provided by simulations with the Spectral Element Ocean Model (SEOM; Haidvogel \& Beckmann, 1999; Iskandarani, personal communication). SEOM has been developed for the purpose of high-resolution, basin-scale modeling on unstructured global grids (Iskandarani, Haidvogel, \& Boyd, 1994). Two separate global-scale implementations of SEOM have been developed to generate tidal and sub-tidal information for use by the regional model. In each case, the finest resolution of the horizontal grid was focused on the North Pacific (Fig. 2). For the 2-D tidal runs, the governing equations are the shallow water equations. For sub-tidal runs, the governing equations are the 3-D, Reynolds-averaged, Navier Stokes equations with Boussinesq and hydrostatic assumptions. The 3-D model was implemented in layered form, with a total of five isopycnal layers. Further details of the structure, forcing, and performance of the 3-D global model are provided in Appendix A.

\subsubsection{The regional model}

For regional circulation in the CGOA, we employed the S-Coordinate Rutgers University Model (SCRUM) of Song and Haidvogel (1994). This free surface, primitive equation model uses curvilinear orthogonal coordinates in the horizontal, and a stretched, bottom following 's-coordinate' allowing flexible spacing of vertical grid points. The latter feature is especially useful in resolving boundary layers near the surface (important for wind mixing) and near the bottom (important for tidal mixing). Initial experiments comparing a curvilinear coast following coordinate system to the present rectilinear system established the latter as the more economical choice for the highly curved CGOA coastline. Ultimately, we implemented the model on a rectilinear grid oriented at $38^{\circ}$ to true north (Fig. 3), with bathymetry derived from ETOPO5 and finer-scale bathymetric data (Fig. 4). In SCRUM, land areas are 'masked out' after the calculation of each timestep, and thus entail computational overhead. Our rotated grid is designed to cover coastal and basin areas of the GOA efficiently, while minimizing coverage of land areas to enhance computational efficiency. Further details of the structure, forcing and performance of the regional model are provided in Appendix B. Here, we shall focus on the method employed for coupling global and regional models. 


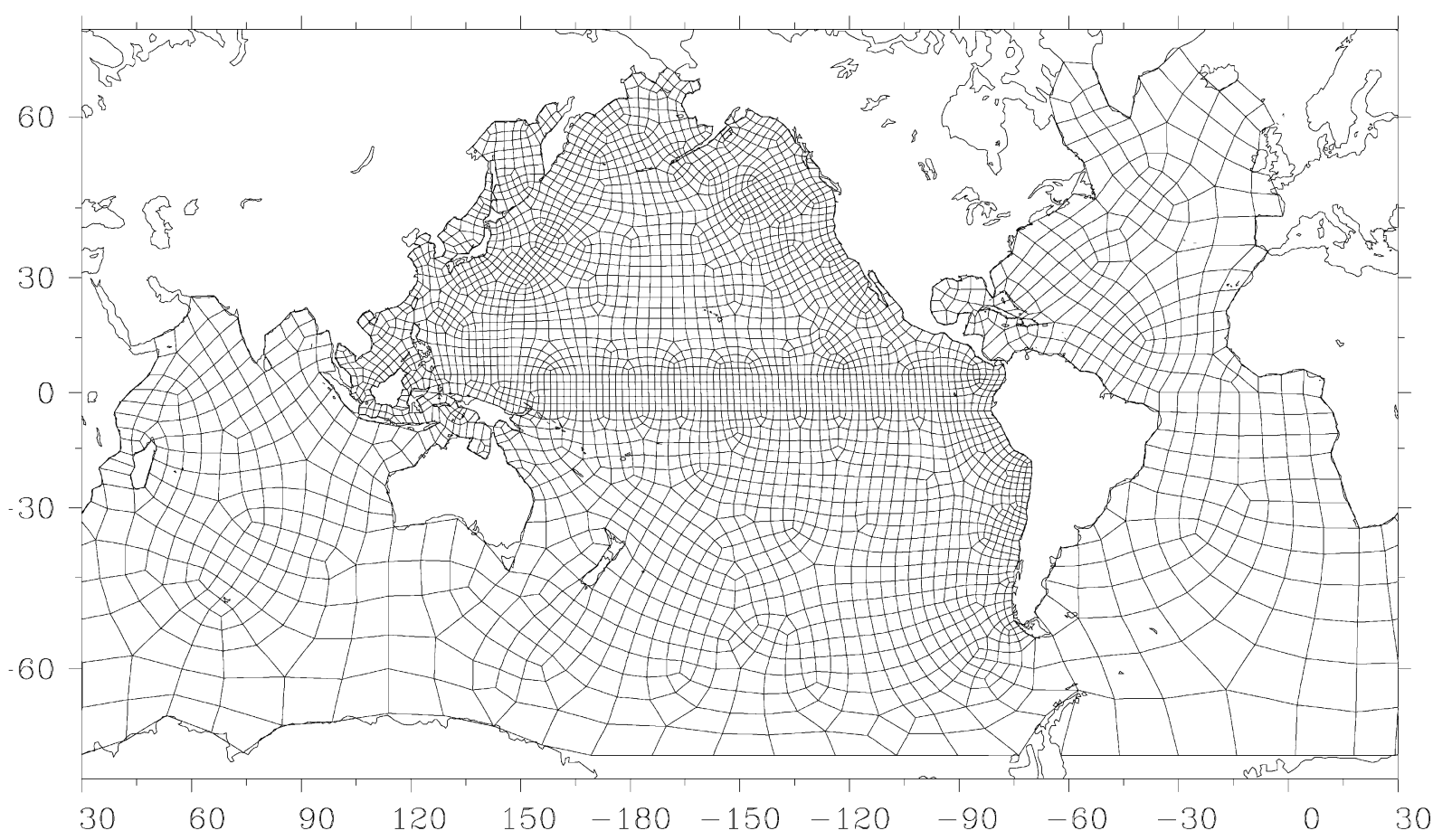

Fig. 2. Layout of quadrilateral elements for the layered implementation of the Spectral Element Ocean Model (SEOM). Structure within each quadrilateral is represented with a polynomial basis set of order eight. The resulting average 'grid spacing' is approximately $25 \mathrm{~km}$ around the periphery of the North Pacific Basin, and increases to about $100 \mathrm{~km}$ elsewhere.

\subsection{Model coupling}

Perfect open boundary conditions, i.e. ones which simultaneously allow incoming external information to enter unimpeded and internally generated signals to exit without distortion, are difficult to approximate and almost certainly impossible to achieve fully. Many variants on open boundary condition techniques have been explored, although most have considered either tidal (e.g. Flather, 1976) or sub-tidal (e.g. Marchesiello, McWilliams, \& Shchepetkin, 2001) variability separately. In contrast, in our CGOA regional model, we have the need to impose simultaneously both tidal and sub-tidal information from the external ocean. One sensible approach is to avoid open boundaries entirely through the use of a telescoped grid and a simple closed box (see Fig. 3). This method of incorporating the global model information is in some ways an extension of the boundary condition technique of Hermann and Stabeno (1996), in which a telescoped grid and closed box were utilized for a regional model with a rigid lid. The rigid lid approximation allowed a simple specification of the total barotropic flux through the coastal domain (representing the broad influence of large-scale patterns) without constraining the small-scale details of the flow. In the present case of our free surface model, a different technique is required. Within the telescoped box, adjacent to the finely resolved area of interest, are placed nudging bands where currents and tracers are nudged towards desired sub-tidal values, but not so strongly as to prevent the escape of (e.g. substantially reflect) any outgoing, internally generated mesoscale signals.

The revised governing equation for a nudged variable $A$ is then:

$$
\mathrm{d} / \mathrm{d} t\{A[x, y, x, t]\}=(\text { dynamical terms })+\alpha[x, y] *\left(A_{\text {global }}-A\right)
$$

Here $A$ is the nudged variable, $A_{\text {global }}$ is the exterior value (e.g., from the global model), 'dynamical terms' 


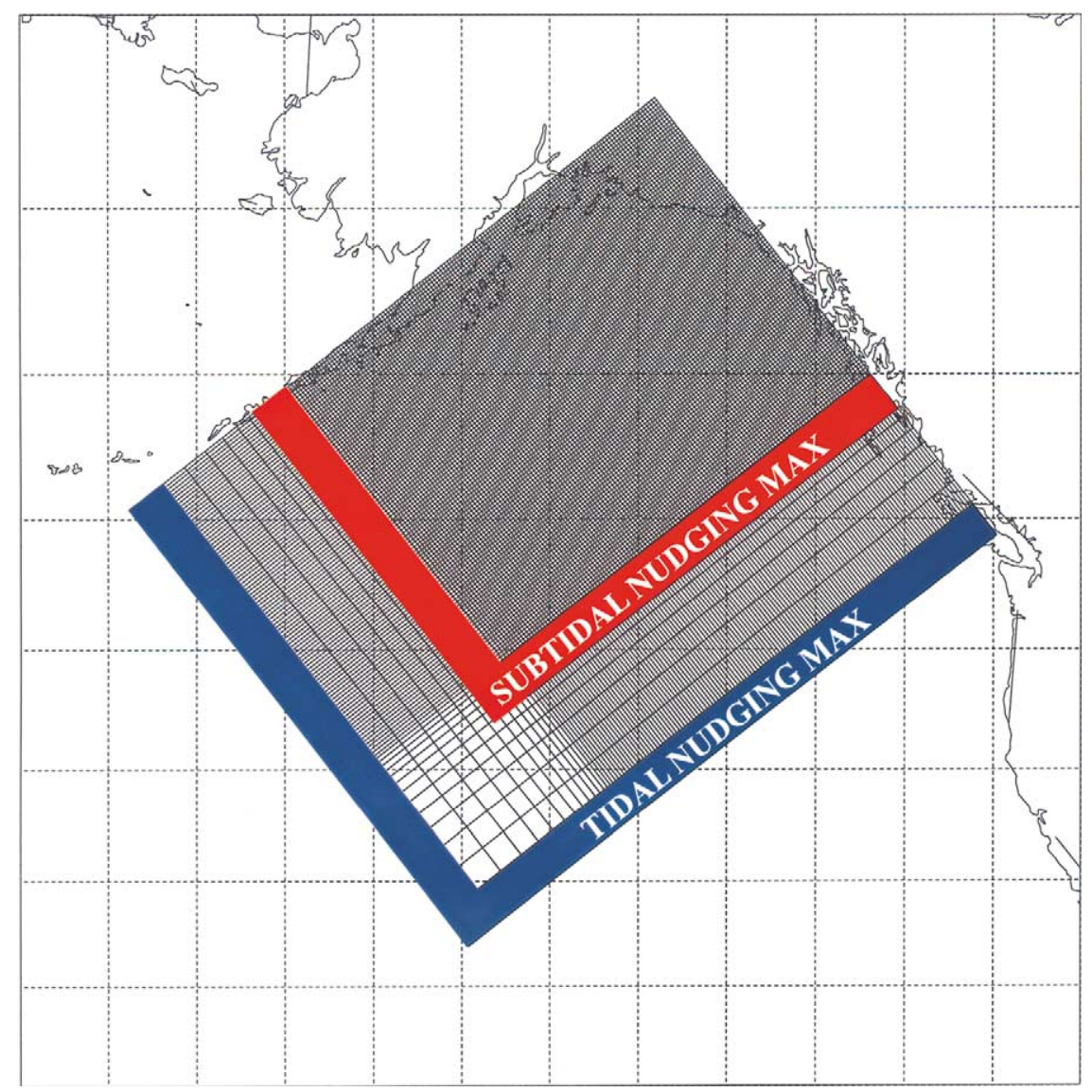

Fig. 3. Layout of the telescoped rectilinear grid for our regional implementation of the S Coordinate Rutgers University Model (SCRUM). Regions of maximum tidal and sub-tidal nudging, respectively, are indicated.

represents all the model physics (advection, diffusion, acceleration, etc.) and $\alpha$ is the nudging constant. We note that such nudging is, in fact, a very primitive form of data assimilation, and that it has been used as a component in other open boundary condition techniques (e.g. Marchesiello et al., 2001; Palma \& Matano, 1998a,b). Note also that $\alpha$ varies in space, having nonzero values in specified bands but elsewhere set to zero elsewhere. In the present set of models, the nudged variables are as follows: $T$ and $S$ (three dimensional fields from monthly climatologies); depth-averaged $U$ and $V$ (two-dimensional fields from the global sub-tidal layered model runs), and free-surface height (two-dimensional fields from the global tidal runs).

The regional model treats the external (depth-averaged) mode as a separate variable, which greatly simplifies the nudging process. Although three-dimensional nudging of $U$ and $V$ is certainly possible, there are many unresolved issues related to the transfer of layered model information onto a level model. Here, for simplicity, we have focused on the effectiveness of two-dimensional information, as a means of conveying tidal and sub-tidal information; a fuller exploration of three-dimensional layer-level coupling schemes is anticipated for future models of this region.

The external boundary values $A_{\text {global }}$ may be based on data, the results of a large-scale model simulation, or some combination of the two. For sub-tidal flows, the area between the sub-tidal nudging band and the solid wall is intended to function as a free recirculation zone, satisfying continuity and possibly absorbing 


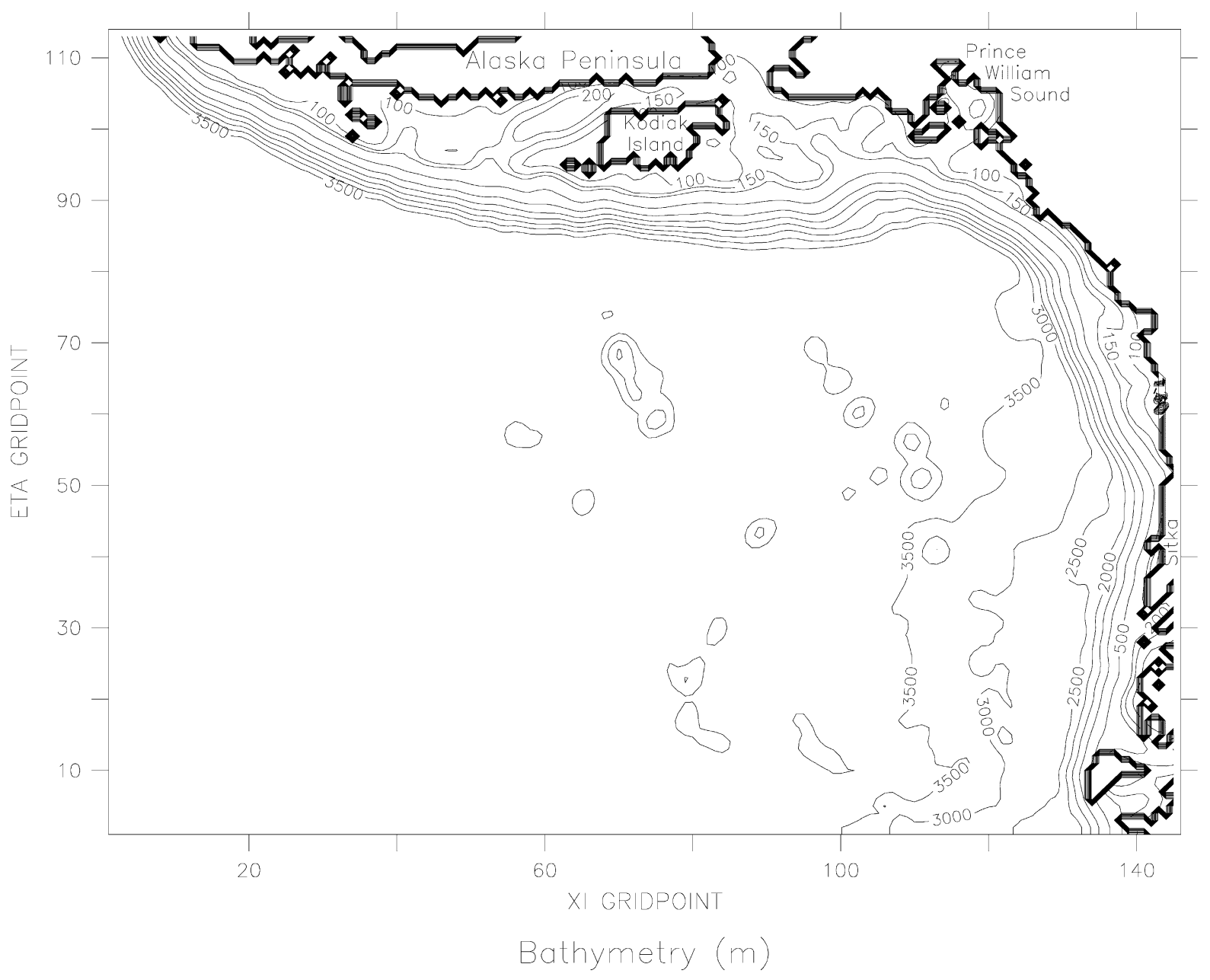

Fig. 4. Smoothed bathymetry used for the regional model simulations. In this and subsequent regional model results figures, the axes are aligned with those of the model (that is, rotated $38^{\circ}$ relative to true north), and units are model gridpoints in the two coordinate directions ('xi' and 'eta'). Distance between successive gridpoints ranges from 13-22 km.

any mesoscale features that escape from the interior. Relevant information from the sub-tidal model will include internal wave modes, in particular coastal-trapped waves (CTWs) that propagate with the coast to their right. How strongly the regional model values should be nudged toward their counterparts from the global model is directly dependent on the time it takes a CTW characteristic to traverse the nudging band. For a nudging band which is $1000 \mathrm{~km}$ wide, and a wave speed of $1000 \mathrm{~km} \mathrm{~d}^{-1}$, the time of transit is $\sim 1$ d. Hence, for CTWs, a nudging constant (alpha) of $\sim 1 \mathrm{~d}^{-1}$ is a reasonable choice for significant nudging of the regional model values toward their global model counterparts.

This nudging constant is also a reasonable choice for substantial damping of mesoscale signals, which are leaving the finely resolved region; for example, it ensures that any CTW signal, which is not present in the global model result, will be significantly attenuated before entering the free re-circulation region beyond the sub-tidal nudging band. Such outward-propagating mesoscale features, which escape the damping effects of the sub-tidal nudging band (or are created by the nudging to global model values), will be 
attenuated further by their transit across the telescoped region, through absorption into the larger-scale flows resolved by the coarser grid. Whatever signal is left may reflect off, or propagate along, the solid wall, and potentially may encounter the sub-tidal nudging band a second time, where further attenuation (or reflection back out into the re-circulation zone) will take place. Some of these spurious gradients will result from the 'escaped' signals from the interior, others will result from the interaction of the solid walls with local wind forcing (which is applied over the entire model domain). Again, the sub-tidal nudging band acts as a barrier to shield the interior from these spurious signals, and a significantly large damping constant (such as the $1 \mathrm{~d}^{-1}$ value suggested above) will provide much of the needed attenuation.

Tidal information from the global model represents traveling waves, and a tidal nudging band requires nudging constants large enough to transmit this global signal to the regional model. In water that is 4000 $m$ deep (the maximum depth of the regional model), the free wave speed of shallow water waves is approximately $200 \mathrm{~m} \mathrm{~s}^{-1}$. Hence, for a tidal nudging band $1000 \mathrm{~km}$ wide, the time of transit for tidal characteristics crossing the band is $\sim 1 \mathrm{~h}$, and a nudging constant of $\sim 1 \mathrm{~h}^{-1}$ is appropriate.

In order to accommodate both tidal and sub-tidal dynamics in the present model, we employ the two independent (though spatially overlapping) nudging bands simultaneously-that is, two separate areas where the regional model assimilates tidal and sub-tidal information, respectively, from the larger-scale model and/or from observational data. Tidal elevations (here, the five most energetic tidal components) are assimilated in the tidal nudging band near the western and southern walls of the (telescoped) regional model domain. Temperature, salinity, and barotropic velocity fields, corresponding to the desired sub-tidal inflows, are assimilated along the sub-tidal nudging band further within the domain, but are still external to the finely resolved CGOA (see Fig. 3).

Ideally, the tidal signals assimilated in the outer domain will be transmitted through areas of sub-tidal nudging without attenuation. In practice this transmission will depend on the value of the sub-tidal nudging constants for scalars and velocity, the width of the sub-tidal nudging band, the frequencies of the tidal signals, and the phase speeds of the tidal signals. As an estimate of attenuation, consider the one-dimensional shallow-water wave equations with nudging of tidal height and sub-tidal velocity:

$$
\begin{aligned}
& \eta_{\mathrm{t}}=-H U_{x}+\alpha^{\mathrm{T}}\left(\eta^{\mathrm{T}}-\eta\right) \\
& u_{\mathrm{t}}=-g \eta_{x}+\alpha^{\mathrm{S}}\left(u^{\mathrm{S}}-u\right)
\end{aligned}
$$

where $\eta$ is the free surface height above mean fluid depth $H, u$ is the horizontal velocity, $\eta^{\mathrm{T}}$ and $u^{\mathrm{s}}$ are the tidal height and sub-tidal velocity to be assimilated (from a large scale model and/or data), and $\alpha^{\mathrm{T}}$ and $\alpha^{\mathrm{S}}$ are the tidal and sub-tidal nudging constants, respectively. We seek approximate solutions for tidal motions within the sub-tidal nudging band. In a region where $\alpha^{\mathrm{T}}=0$ and where both $u^{\mathrm{S}}$ and $\alpha^{\mathrm{S}}$ vary slowly in space, Eqs. (1) and (2) yield:

$$
\eta_{\mathrm{tt}}-c^{2} \eta_{\mathrm{tt}}+\alpha^{\mathrm{s}} \eta_{\mathrm{t}}=0
$$

A characteristic equation is obtained by looking for solutions of the form:

$$
\eta=\eta_{0} \exp [i(k x-\omega t)]
$$

where $\omega$ may have an imaginary component. Substitution into (3) yields

$$
\omega=\left\{-i \alpha^{\mathrm{S}} \pm\left[-\left(\alpha^{\mathrm{S}}\right)^{2}+4 c^{2} k^{2}\right]^{1 / 2}\right\} / 2
$$

If the nudging coefficient $\alpha^{\mathrm{S}}$ is sufficiently small and the tidal frequency $\omega^{\mathrm{T}}$ (=kc, with units of $\operatorname{rad~s}^{-1}$ ) is significantly large, then

$$
4 c^{2} k^{2} \gg\left(\alpha^{\mathrm{S}}\right)^{2}
$$

Under these circumstances, the solution for an incident tidal signal in the sub-tidal nudging band can be approximated as 


$$
\eta=\eta_{0} \exp \left[i\left(k x-\omega^{\mathrm{T}} t\right)\right] \exp \left[-\left(\alpha^{\mathrm{s}} / 2\right) t\right]
$$

Now, integrating a tidal characteristic $\left(\mathrm{kx}-\omega^{\mathrm{T}} \mathrm{t}\right)$ across a sub-tidal nudging band of width $\mathrm{dx}$, the fractional attenuation of tidal amplitude due to passage through that band is

$$
F=1-\exp \left[-\left(\alpha^{\mathrm{s}} / 2\right) d x / c\right]
$$

For typical values in our model $\left(d x=1000 \mathrm{~km}, c=200 \mathrm{~m} \mathrm{~s}^{-1}\right.$ and $\left.\alpha^{\mathrm{s}}=10^{-5} \mathrm{~s}^{-1}\right), F$ is negligible. Indeed, even if sub-tidal nudging occupied the entire finely resolved region $\left(d x=\sim 2 \times 10^{6} \mathrm{~m}\right)$, the value of $F$ would be of order 0.1 . Hence, barring substantial reflection of the tidal signal at the edge of the sub-tidal nudging band, we will have clear transmission of the tidal signal into (and back out of) the model's interior.

To obtain the $A_{\text {global }}$ values for tracers, daily $\mathrm{T}$ and $\mathrm{S}$ climatologies for each model gridpoint were interpolated from the monthly values of Levitus (Levitus, Burgett, \& Boyer, 1994), while daily mean subtidal velocities were obtained from the results of the global layered model. The Levitus values are themselves derived from a comprehensive set of $\mathrm{S}$ and $\mathrm{T}$ observations, averaged in time and objectively interpolated in space onto a regular, $1^{\circ}$ global grid. Insufficient data exist to apply more spatially refined values, specific to a particular year, along our sub-tidal nudging band.

For tidal nudging, we first ran the regional model without tides (that is, with only sub-tidal barotropic velocity and T, S climatology nudging) and stored daily averages of sea surface height at each gridpoint. These data were added to tidal heights calculated from spatially dependent amplitudes and phases derived from the 2-D tidal run of SEOM, which included M2, S2, N2, K1, and O1 tidal components. Note that without adding the daily average height estimates from the sub-tidal run, the boundary of the regional model in the tidal-plus-sub-tidal run would be strongly nudged towards a mean zero elevation (that is, the purely tidal signal), which could potentially distort the sub-tidal dynamics of the interior.

For the sub-tidal nudging band, we apply a maximum nudging constant of $\alpha^{\mathrm{TS}}=0.1 \mathrm{~d}^{-1}$ for climatological $\mathrm{T}$ and $\mathrm{S}$ and $\alpha^{\mathrm{UV}}=1.0 \mathrm{~d}^{-1}$ for sub-tidal velocities. For the tidal nudging band, we apply the substantially larger maximum value of $\alpha^{\text {tidal }}=1.2 \times 10^{2} \mathrm{~d}^{-1}$ for surface heights. The values of $\alpha^{\mathrm{TS}}$ and $\alpha^{\mathrm{UV}}$ are ramped in space, from zero at the outer solid wall of the regional model, to their maximum values near the boundary of the telescoped and non-telescoped regions 10 gridpoints $(\sim 856 \mathrm{~km})$ into the interior. Between gridpoints 10 and $17(\sim 120 \mathrm{~km})$, they are ramped back to zero. The values of $\alpha^{\text {tidal }}$ are ramped as well, from their maximum value at the outer solid wall to a value of zero 17 gridpoints $(\sim 1000 \mathrm{~km})$ into the interior. This ramping is designed to minimize reflection and encourage absorption of any internally generated signals.

\subsection{Float tracking}

The paths of numerical drifters can be compared with drogued drifter data. For this purpose, stored daily averaged velocities from the regional model (lowpass-filtered to remove tidal and near-inertial signals) are interpolated to $5 \mathrm{~m}$ and $40 \mathrm{~m}$ depth, and used to generate pseudo-Lagrangian float tracks using a fourthorder Runge-Kutta routine.

\section{Model experiments}

We ran several model experiments to test features of the coupling scheme and performance of the regional and global models. The experiments conducted are as follows:

(1) Global model run. The global 3-D model is spun up with 5 years of a repeating cycle of daily NCEP winds, spanning the period of NSCAT wind availability (Aug 1996-July 1997). Resulting depth integrated velocities are low pass filtered and stored as daily values for use by the regional model. 
(2) Regional model runs. Here we utilize the monthly climatologies (Levitus) for T and S, daily barotropic velocities from the global model, and tidal elevations for the global model, as fields to be applied to the nudging bands in the regional model. Wind, heat flux, and coastal runoff are applied as forcing fields (see Appendix B for details), and the model is run for the period August-December 1996, when applicable SEOM results are available. The results are compared with observational data for this period.

(2a) Climatological tracers and sub-tidal velocity nudging. In the first nudging experiment, the regional model is spun up via nudging during July 27-August 1 with daily barotropic velocities (from SEOM), and monthly T, S fields (from Levitus climatology). For this spin-up period only, nudging coefficients are applied that are uniform in the finely resolved domain $\left(1.0 \mathrm{~d}^{-1}\right.$ for $\mathrm{U}, \mathrm{V} ; 0.1 \mathrm{~d}^{-1}$ for $\left.\mathrm{T}, \mathrm{S}\right)$, and linearly decrease to zero at the outer edges of the (telescoped) domain. This pattern of assimilation allows the interior to assume the SEOM velocity values, without forcing any flows through the solid walls. Subsequent to the five-day spin-up, the model is nudged only in the telescoped domain, with nudging coefficient values as described in Section 2.2 (linearly decreasing to zero at the edge of the finely resolved domain and at the outer walls of the telescoped area). The initial spin-up period provides the essential broad patterns of the flow field, including some of the larger eddies. Subsequently the regional model is free to develop finer scale circulation in its interior, under the influence of local wind and buoyancy forcing, and with the SEOM barotropic velocities and climatological $\mathrm{T}$ and $\mathrm{S}$ applied as horizontal boundary conditions.

(2b) Climatological tracers, sub-tidal velocities, and tidal elevation nudging. After the sub-tidally nudged run is complete, an equivalent tidal-plus-sub-tidal run is performed, which has boundary conditions partially determined by the sea surface elevations of the first run as described in Section 2.2. Results from this run are used for the model-data comparisons reported in Section 4.2.3.

(2c) Climatological tracer nudging only. The model is spun up as in case (2a). Subsequently, however, we remove all influence of the SEOM velocities, and assimilate only the climatological T, S as a horizontal boundary condition.

By contrasting these three runs, we attempt to clarify the influence of global barotropic tidal and sub-tidal information on the interior regional solution.

\section{Results}

\subsection{Global model results}

Figs. 5 and 6 display barotropic velocities and free surface height fields from the global model interpolated to a regular latitude longitude grid for early June and early November, respectively. Coastal and shelf break currents are evident, as are meanders and eddies in the deep basin. A significant portion of the shelf break current in the northwestern GOA (the Alaskan Stream) appears to come from the deep basin in these simulations, whereas currents upstream (the Alaska Current) are weak. The Alaskan Stream is wider in the model output than is typically observed, as a result of the limited spatial resolution and smoothed bathymetry (see Appendix A). In early November, westward flow of the Alaska Coastal Current is spatially continuous around the GOA. However, results for early June exhibit a significant reversal of that near coastal flow in the eastern GOA. This pattern of seasonal variation in the coastal currents in the eastern GOA has been noted by Royer (1998) and is suggested by the analyses of seasonal altimetric patterns of Strub and James (2002a). 


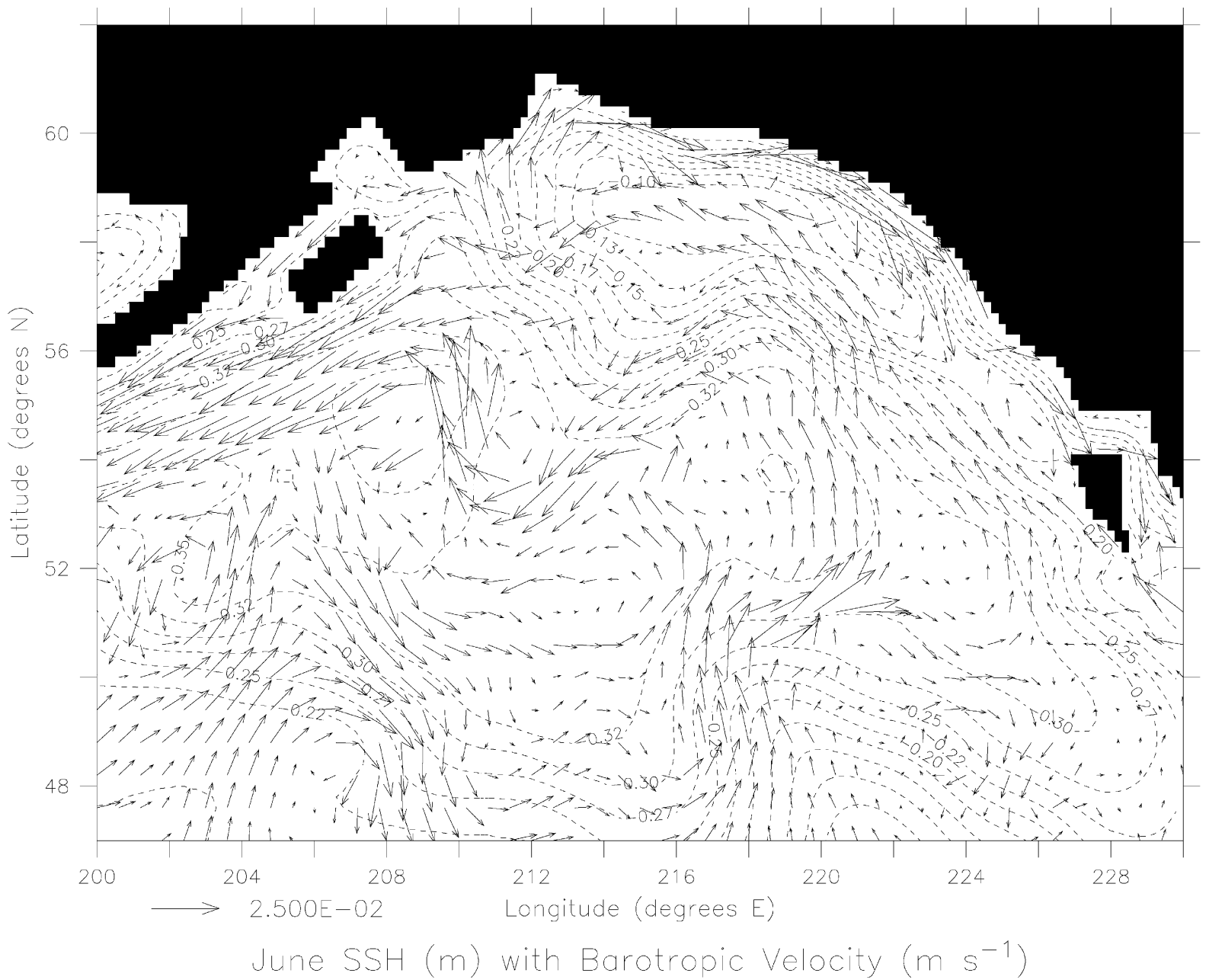

Fig. 5. 3-D Global model SSH (contoured, m) and barotropic velocity ( $\mathrm{m} \mathrm{s}^{-1}$ ) for DOY 155 (June).

\subsection{Regional model results}

Here we describe results from the 1996 regional run 2b, which included all three types of nudging (climatological S and T, sub-tidal barotropic velocity, tidal elevation). We begin with an overview of the major features generated by the model, then proceed to a more detailed comparison of model output with data in Section 4.2.3.

\subsubsection{Basin-scale circulation and SST}

Regional model results reproduce many of the major observed features in the CGOA (Figs. 7-8). The AC-AS system and ACC are clearly evident; surface speeds achieve realistic values of $0.4 \mathrm{~m} \mathrm{~s}^{-1}$ and greater. Buoyancy forcing is typically strong in the fall, contributing to the strength and continuity of the ACC in model results. Compared to surface velocities, barotropic velocities are substantially weaker, and are frequently in different directions (compare Figs. 7 and 8). Note, however, that barotropic velocities at the shelf break are generally stronger than their equivalent in the global model run. A tongue of warm 


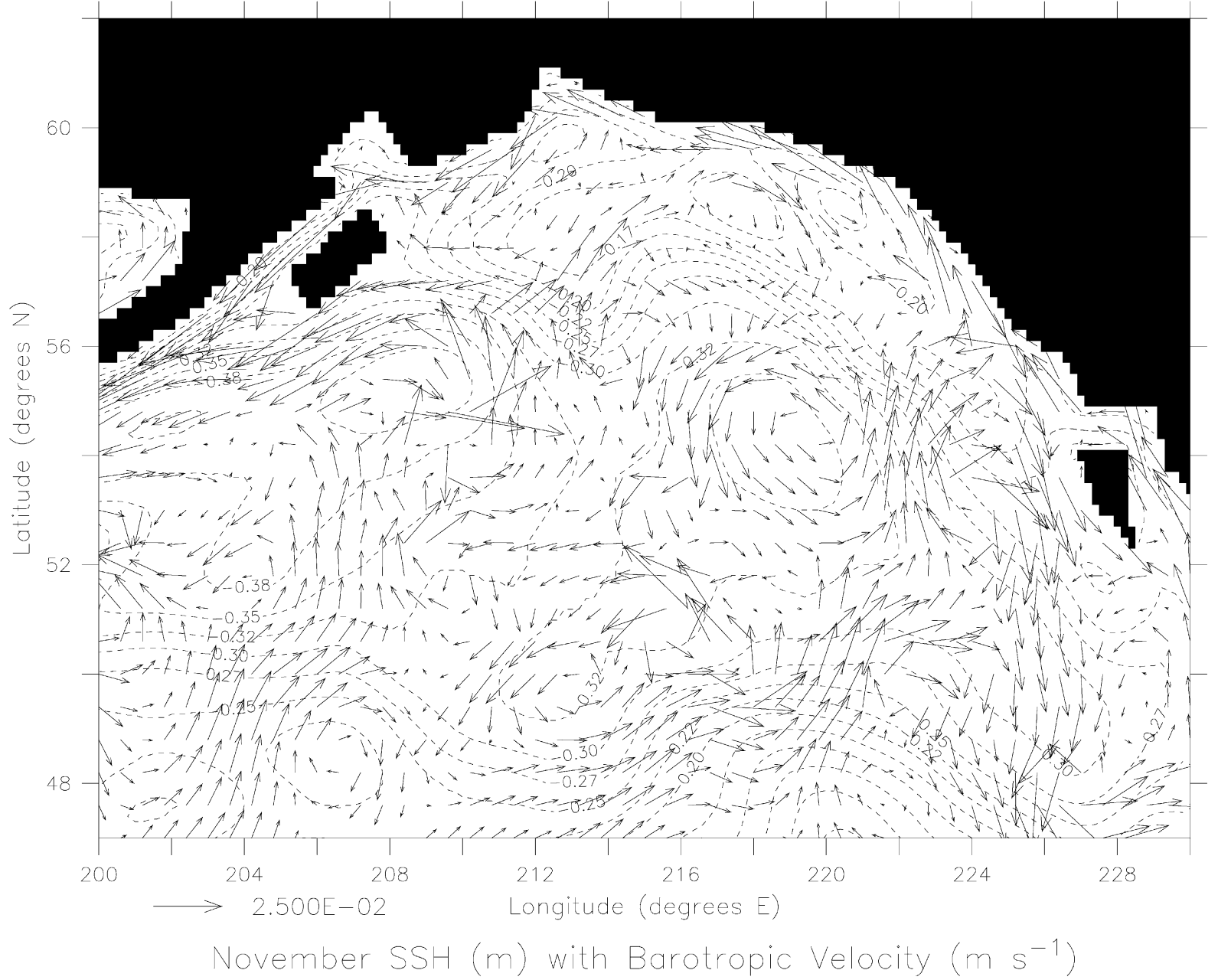

Fig. 6. 3-D Global model SSH (contoured, $\mathrm{m}$ ) and barotropic velocity $\left(\mathrm{m} \mathrm{s}^{-1}\right)$ for DOY 304 (November).

water penetrates west along the shelf break in model results, as has been noted in SST images and in hydrographic data (see comparisons with data in Section 4.2.3).

\subsubsection{Mesoscale circulation and eddies}

Extensive mesoscale circulation features are observed in model output on the continental shelf, at the shelf break, and in the deep basin. Many of the simulated barotropic features are locked to prominent seamounts in the deep basin, and to submarine canyons at the shelf break. Animated results (not shown) exhibit a clockwise propagation of disturbances around the seamounts. Eddy activity at the $200 \mathrm{~km}$ scale is most prominent in the vicinity of Sitka, AK. On the shelf, small eddies with $50-100 \mathrm{~km}$ diameter are produced, but appear less dynamic than has been observed in drogued drifter studies (Stabeno \& Hermann, 1996). Eddy generation via baroclinic instability (abetted by a temporary weakening of the downwelling favorable winds) is a possible source of these smaller, nearshore eddies. 


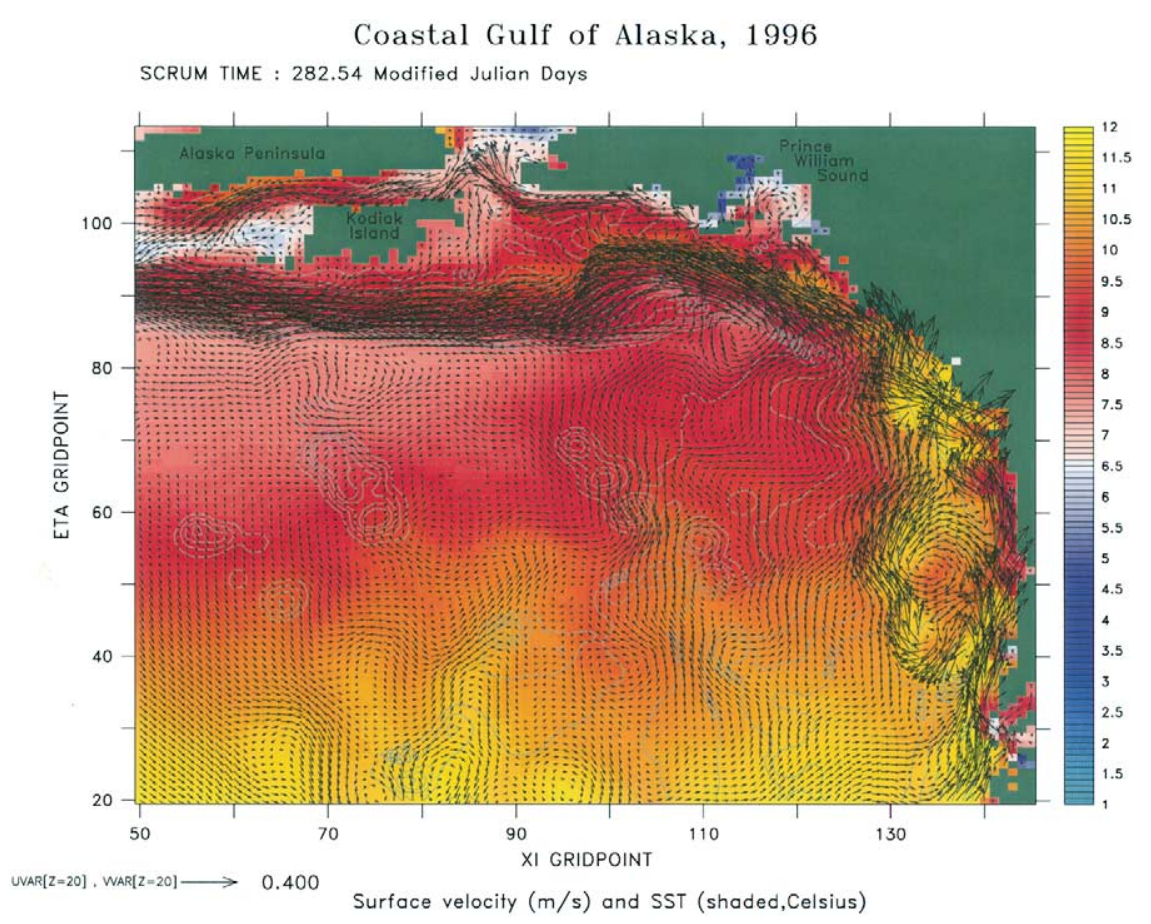

Fig. 7. Regional model surface velocities $\left(\mathrm{m} \mathrm{s}^{-1}\right)$ and temperature $\left({ }^{\circ} \mathrm{C}\right.$, shaded) for 8 October (DOY 282) 1996, with boundary nudging of sub-tidal and tidal information from the global model.

\subsubsection{Comparisons with data}

Here we compare model results for the fall of 1996 to available data of the following types: (1) current meter data and temperature time series from the ACC; (2) drogued drifter tracks from the continental shelf; (3) hydrographic sections corresponding to the ACC and the AS; (4) sea surface temperatures from radiometers; (5) sea surface heights from a coastal tide gauge; and (6) sea surface height perturbations from altimeters. We note areas of agreement, and suggest (here and in Section 5) reasons for observed differences. For this comparison we use the model run $2 \mathrm{~b}$, with both tidal and sub-tidal forcing; subsequently (in Section 4.3) we describe the sensitivity of the results to the inclusion of tidal and barotopic sub-tidal forcing.

4.2.3.1. SST Model SST for October 26, 1996 has been compared with a nine-day composite SST, centered on that date, derived from the NOAA/NASA Oceans Pathfinder archives (Fig. 9; T. Strub \& C. James, personal communication). This date was chosen based on the availability of a clear image. The model reproduces broad features observed in the Pathfinder imagery: a tongue of warm water from the south, penetrating around the CGOA in the direction of the predominant, cyclonic circulation. SST signatures of $200 \mathrm{~km}$-scale meanders and eddies are apparent in both model and data; similar features have been reported by Thompson and Gower (1998). The spatial mean SST produced by the model is lower than that of the data, and spatial gradients tend to be larger than the observations. This lower-than-observed spatial mean can be attributed in part to the Levitus climatology used for initialization and boundary nudging, as the Levitus values for October-November were in fact lower than the observed Pathfinder values for late October 1996.

Several small scale features of the data are captured by the model, as follows:

(a) Structures near Kodiak Island. In both model and data, a near-coastal tongue of warm water, centered 


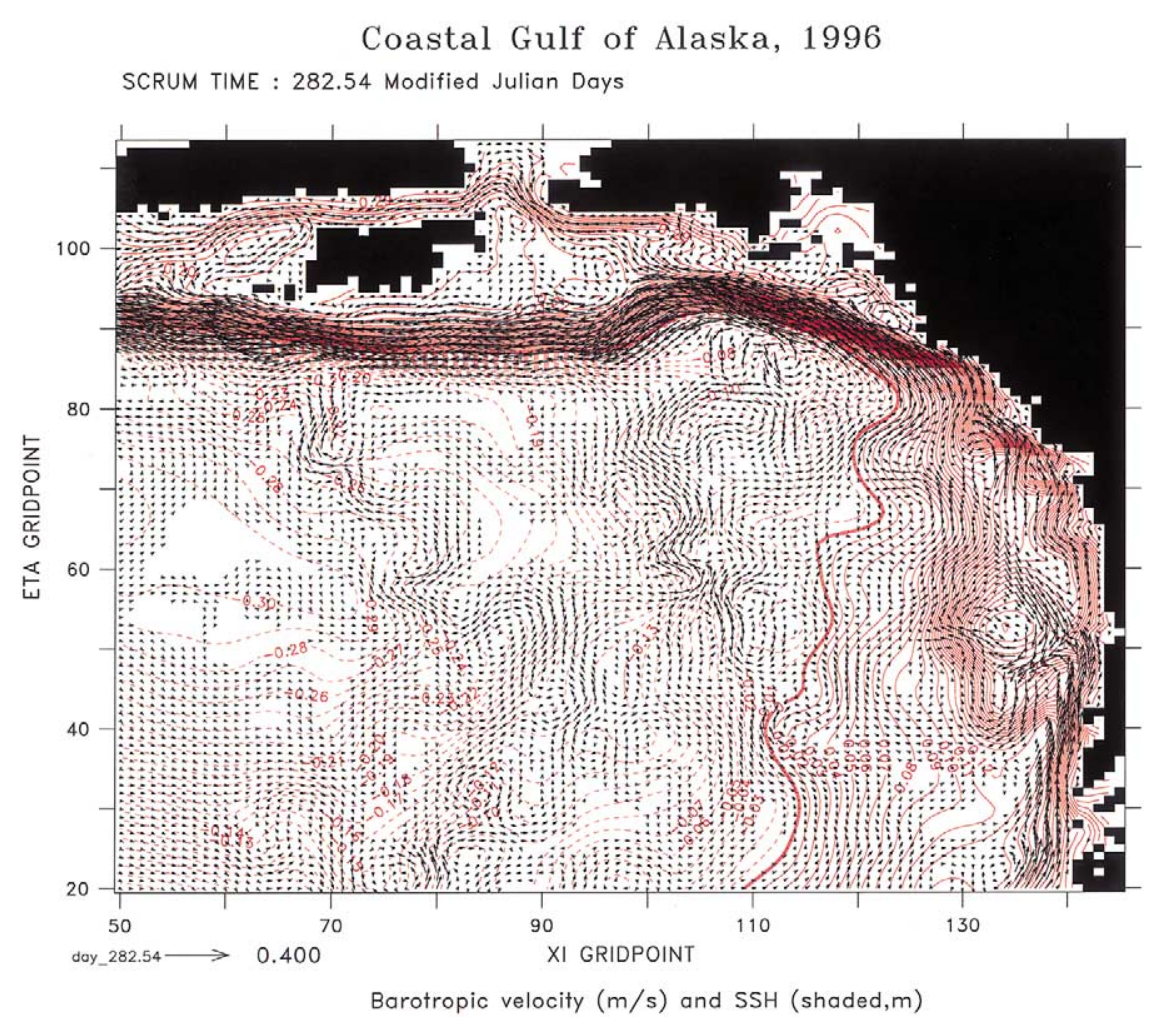

Fig. 8. As in Fig. 7, for barotropic velocities $\left(\mathrm{m} \mathrm{s}^{-1}\right)$ and sea surface height (contoured, $\mathrm{m}$ ).

along the shelf break, bifurcates just east of Kodiak Island. In the model, shallow $(<150 \mathrm{~m})$ areas surrounding Kodiak Island are as much as $4{ }^{\circ} \mathrm{C}$ colder than deeper areas; Cook Inlet is especially cold. The data exhibit the same pattern of cold waters around Kodiak Island, but with only half the amplitude of the model result.

(b) Structures near the Sitka eddy. In the model, relatively warm waters from the south are observed penetrating to the north, along the coastline, past Sitka, AK. Just north of Sitka, a tongue of $\sim 2{ }^{\circ} \mathrm{C}$ colder water streams out from the coast to the south and west. Warmer water swirls anticyclonically around the edge of this colder tongue; we identify this anticyclonic circulation as the 'Sitka eddy' (Tabata, 1982) of our model. In the data, a tongue of warm water perpendicular to the coast is observed penetrating out from approximately the same location as the cold tongue of the model. In both model and data, this tongue appears to represent coastal water. In the model, SST is $\sim 3{ }^{\circ} \mathrm{C}$ colder at the coast than in deeper waters; the data also exhibit cooler waters at the coast, but the temperature difference is only $\sim 1{ }^{\circ} \mathrm{C}$.

4.2.3.2. Hydrographic sections During fall 1996, hydrographic sections were measured across the ACC (at the southwest exit of Shelikof Strait) (Fig. 10) and the AS (at the shelf break, southwest of Kodiak Island) (Fig. 11). In both cases, the model exhibits similar structures in temperature and salinity fields at locations and times corresponding to the hydrographic sections. Across the ACC section, both model and data exhibit highest temperatures at the coastline and near the ocean surface. The model exhibits slightly warmer surface temperatures than the data. In the model, strongest vertical gradients are near the surface; in the data, there is a thermocline at 50-100 m depth. Both model and data exhibit freshest waters at the 


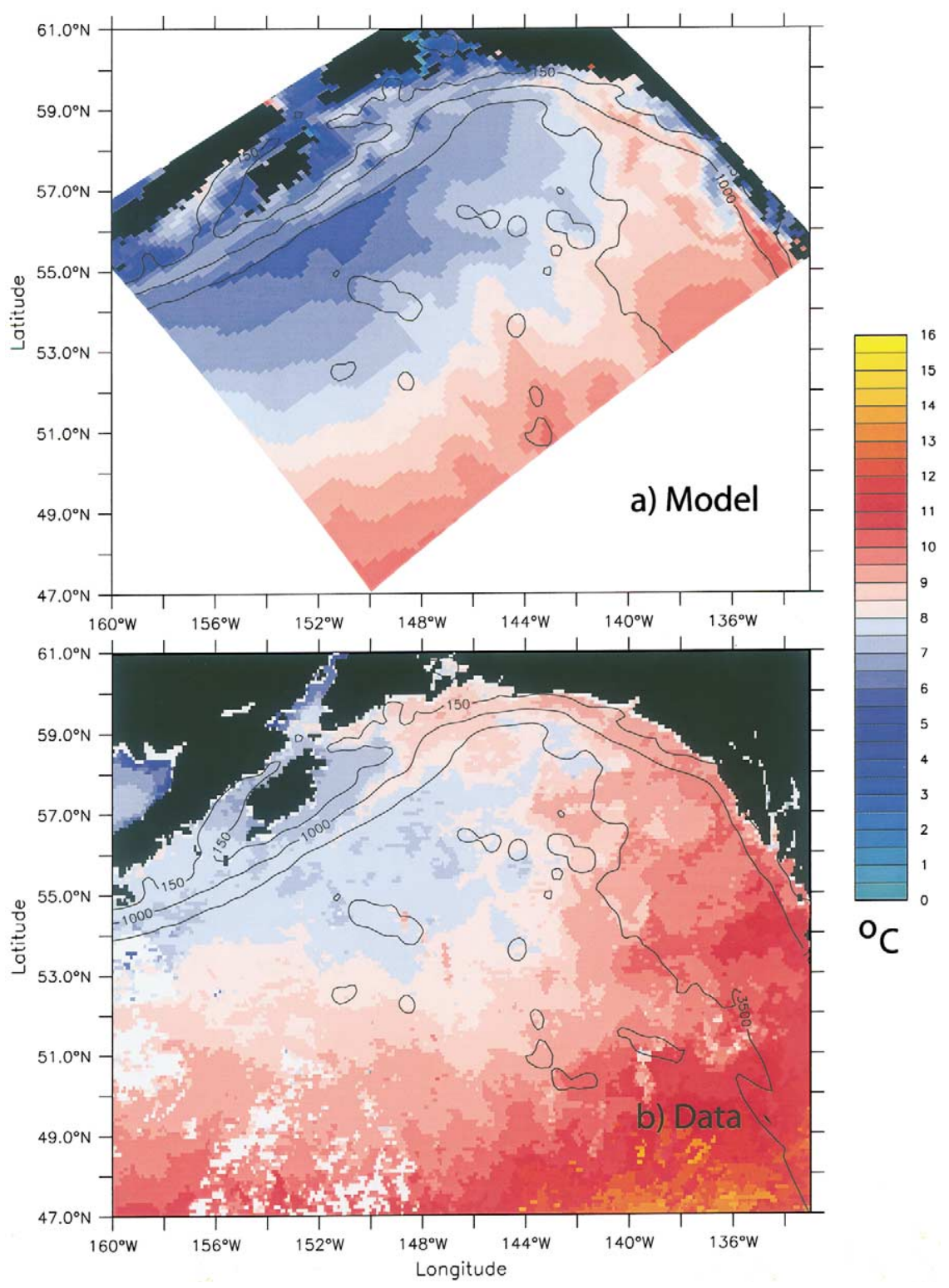

Fig. 9. Comparison of model SST (upper panel) with observed SST (lower panel) from Pathfinder weekly composite $\left({ }^{\circ} \mathrm{C}\right.$ ), for 26 October 1996.

surface in the middle of the strait, rather than at the coast, with slightly stronger vertical gradients in the model. Across the AS section, both model and data exhibit a thermocline at approximately $50 \mathrm{~m}$ depth; the data exhibit a stronger vertical gradient. In the model, SST is slightly warmer to the north; in the data, it is slightly warmer to the south. Both model and data exhibit fresher waters near the shelf break, relative to values further offshore. The weaker vertical gradients in the model are partially the result of limited vertical resolution, especially in the deeper areas (see Appendix B).

A snapshot of model output for early October, 1996, at a location corresponding to the GAK line near 


\section{Model Output}
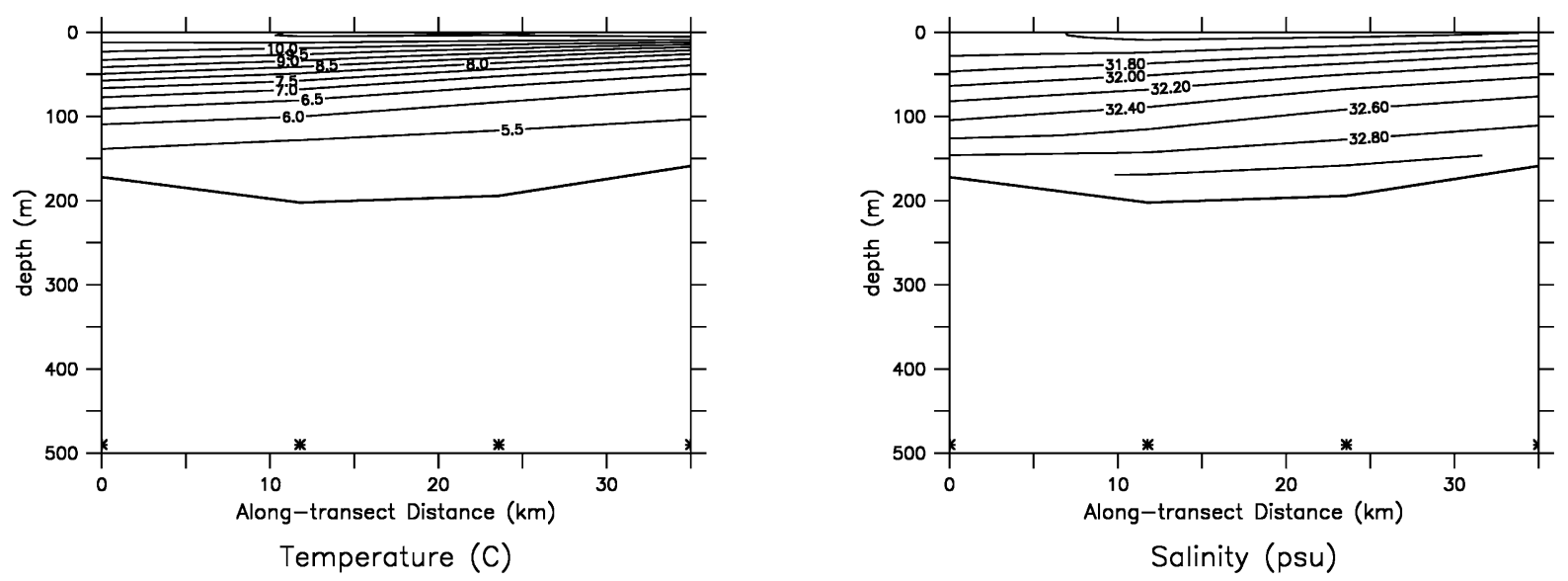

Data Transect
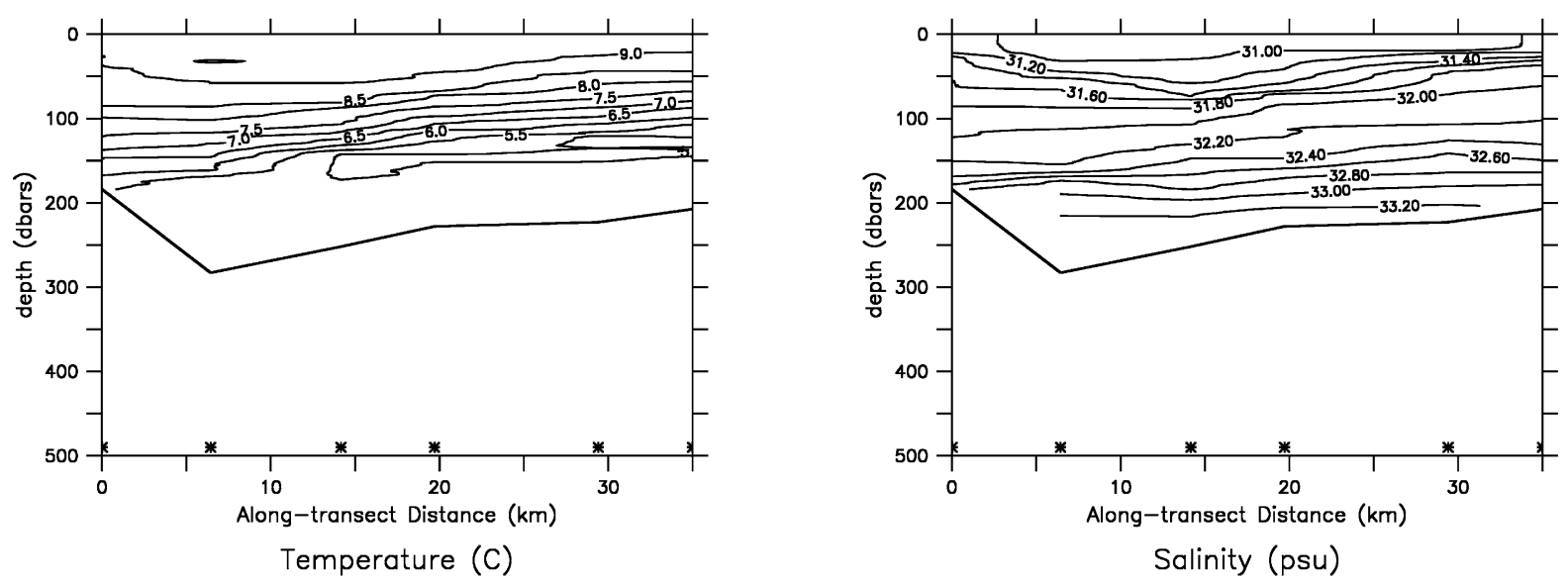

Fig. 10. Modeled (upper) and measured (lower) T (left) and S (right) sections for the Alaska Coastal Current at the southwest end of Shelikof Strait. In each plot, the Alaskan Peninsula is to the left, and Kodiak Island is to the right. Bottom is marked with a heavy line. Model gridpoints and CTD station locations are marked with asterisks.

Seward, AK (Fig. 12), reveals several features typical of fall observations from hydrographic data collected between 1997 and 2000 (T. Weingartner, personal communication). A warm pool of water $\left(10{ }^{\circ} \mathrm{C}\right)$ spans the shelf, with strongest thermocline at $\sim 50 \mathrm{~m}$ depth. A low salinity core $(<30)$ is evident near the coast, and a secondary low-salinity core is evident near the shelf-break. All of these features are present in the hydrographic data. A subsurface maximum in $\mathrm{T}$, similar to that produced by the model, appears in early December data from the GAK line (T. Weingartner, personal communication).

4.2.3.3. Time series of subsurface temperature A time series of temperature for the period 10 August25 September was obtained from a mooring in the center of Shelikof Strait (Fig. 13). The model exhibits 


\section{Model Output}
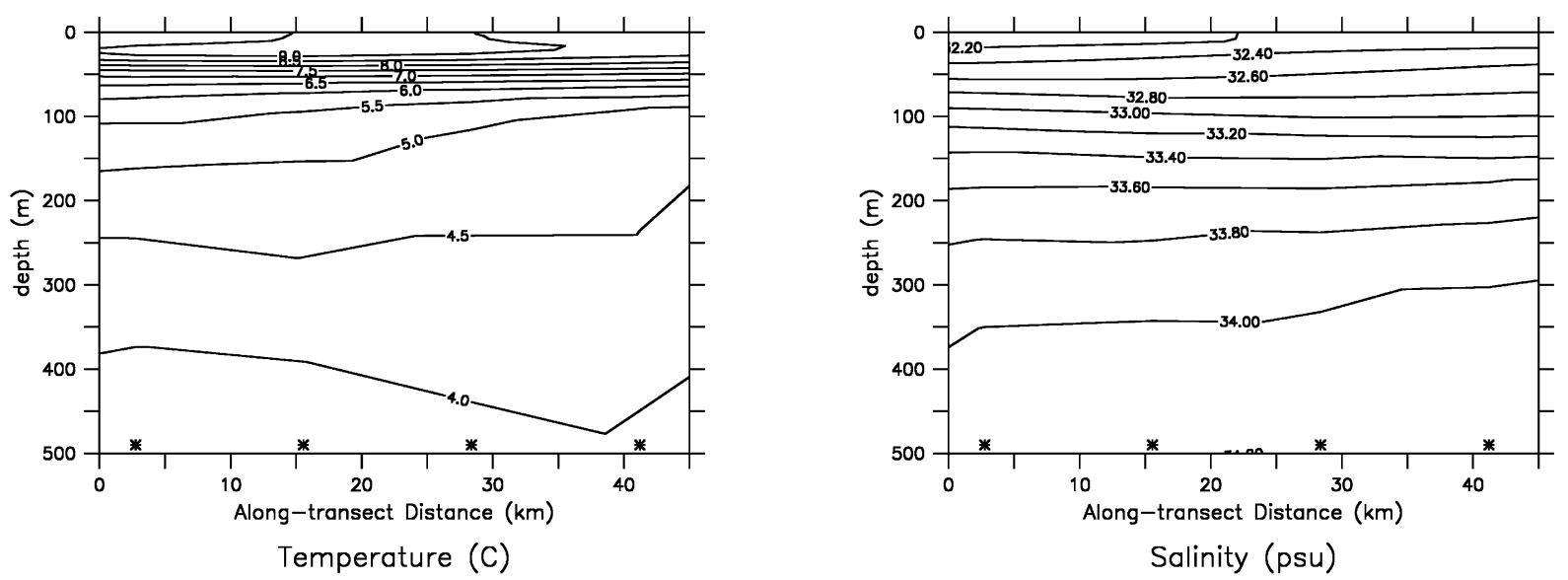

\section{Data Transect}
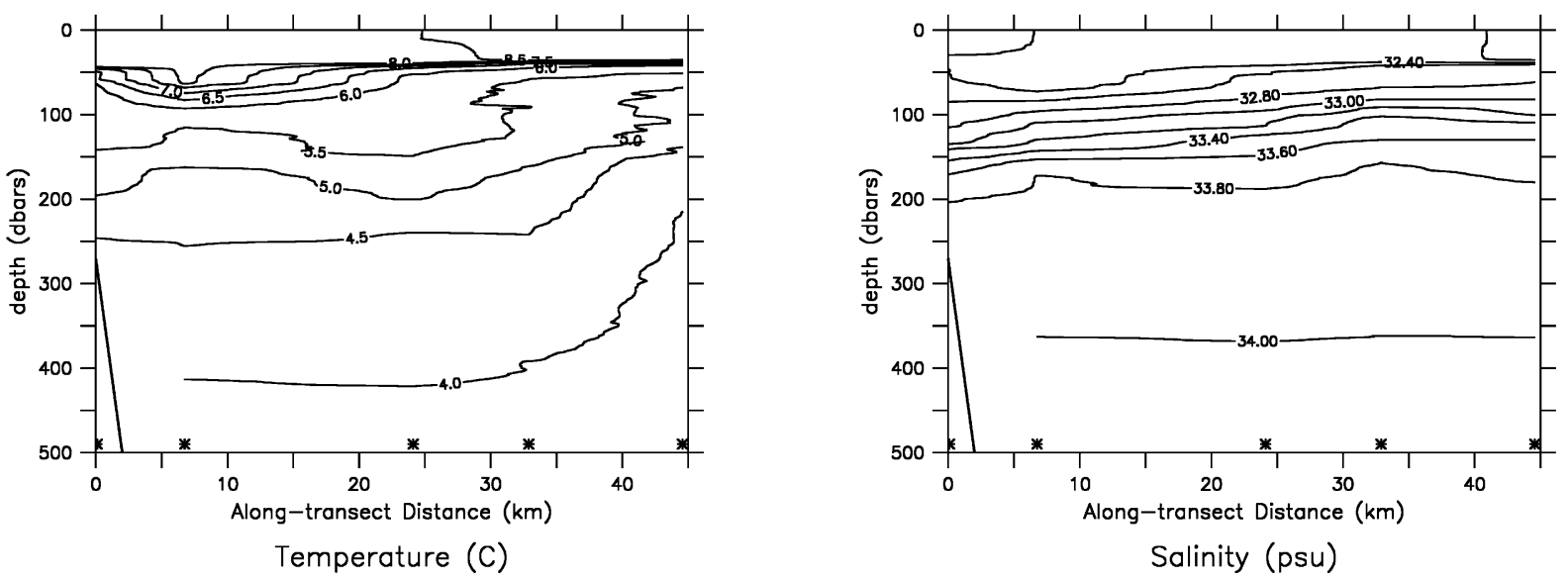

Fig. 11. Modeled (upper) and measured (lower) T (left) and S (right) sections for the Alaskan Stream near the Shumagin Islands. Maximum water depth is $3000 \mathrm{~m}$. Model gridpoints and CTD station sections are marked with asterisks.

a gradual warming trend, with warmest temperatures and strongest gradients near the surface. The data exhibit a similar warming trend, but with more temporal variability; most likely this is because of the passage of $20 \mathrm{~km}$ scale eddies not resolved by the model (see comments below). As in the 26 October SST comparison, the model results here are generally colder (by $\sim{ }^{\circ} \mathrm{C}$ ) than the data.

4.2.3.4. Current meter data Current meter data from the same mooring Shelikof Strait are representative of fall conditions in the ACC (Fig. 14). Surface flows are to the southwest, with a reversal to northeastward flow at depth. As in the temperature data, fluctuations at periods of 3-5 days are common; for the velocity record, these result from both fluctuations in wind stress (resulting from the passage of storms) and the passage of mesoscale eddies. The former should be captured by the present model; the latter is presumably 

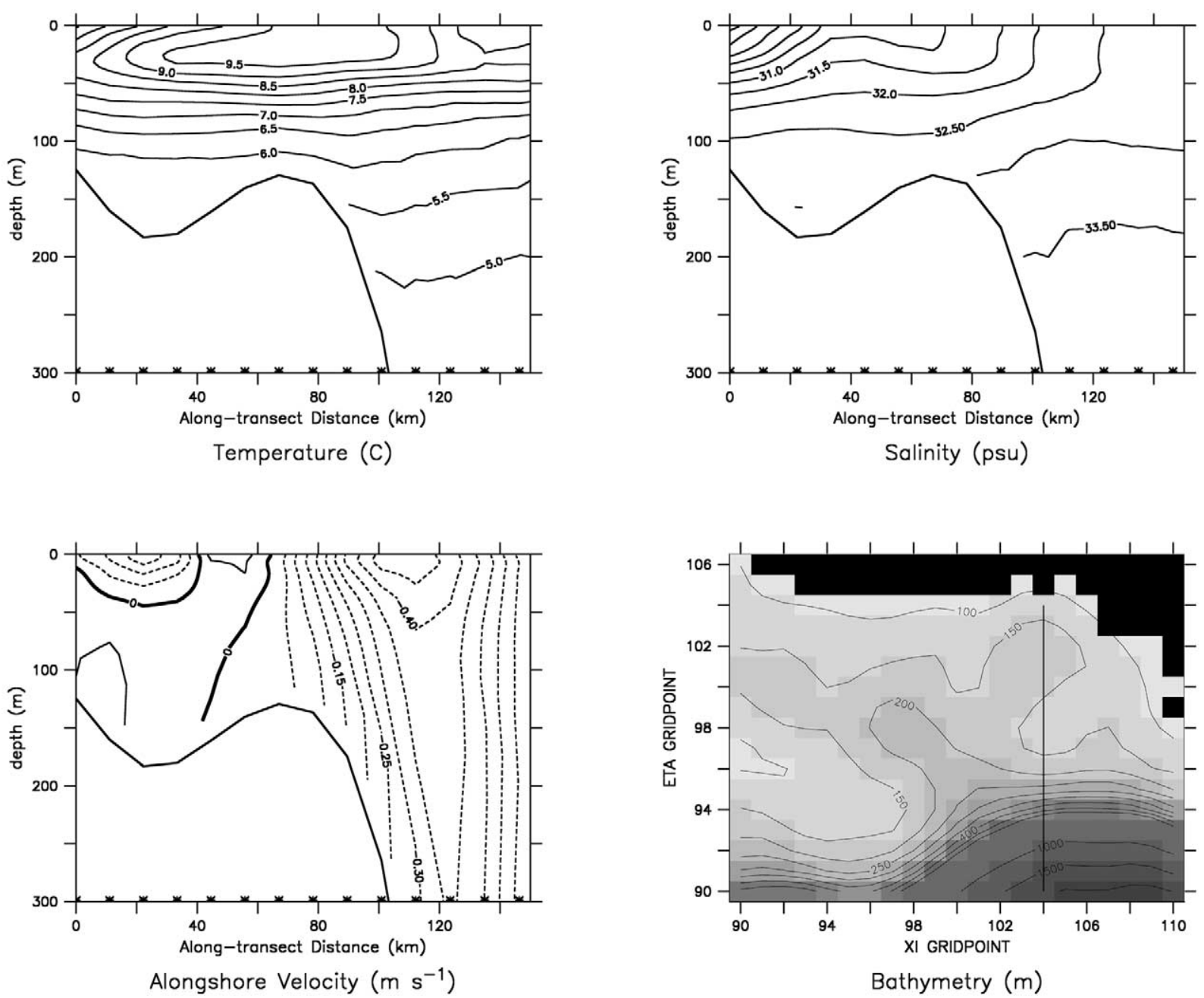

Fig. 12. Modeled sections of T (upper left), S (upper right), and alongshore velocity (lower left) at the GAK line near Seward, AK. Bottom is marked with heavy line. Model bathymetry in the GAK region is also shown (shaded and contoured, m) with Kenai Peninsula (black) and approximate location of GAK line (heavy line).

underestimated by the model because of its limited horizontal resolution. (A model with finer horizontal resolution does capture more of this eddy variability; see Hermann \& Stabeno, 1996; Stabeno \& Hermann, 1996.) While the data exhibit greater variance and stronger amplitudes than the model over the period 3 August-September 1996, specific events, such as strong down-strait flow events in September, appear in both model and data.

There are multiple potential reasons for discrepancies between the modeled and observed ACC, especially at daily time scales. First, winds in Shelikof Strait are frequently ageostrophic (flowing down the pressure gradient, trapped between two mountain ranges on the Alaska mainland and Kodiak Island). This fact can lead to strong differences between measured winds and those calculated from large-scale atmospheric analyses (Stabeno et al., 1995). The NCEP winds presently used for this model do not include such finescale ageostrophic effects; therefore much of the direct down-strait wind forcing is lost. Second, the true bathymetry is rather severe (steep slopes) and the model depths are necessarily smoothed, because of 

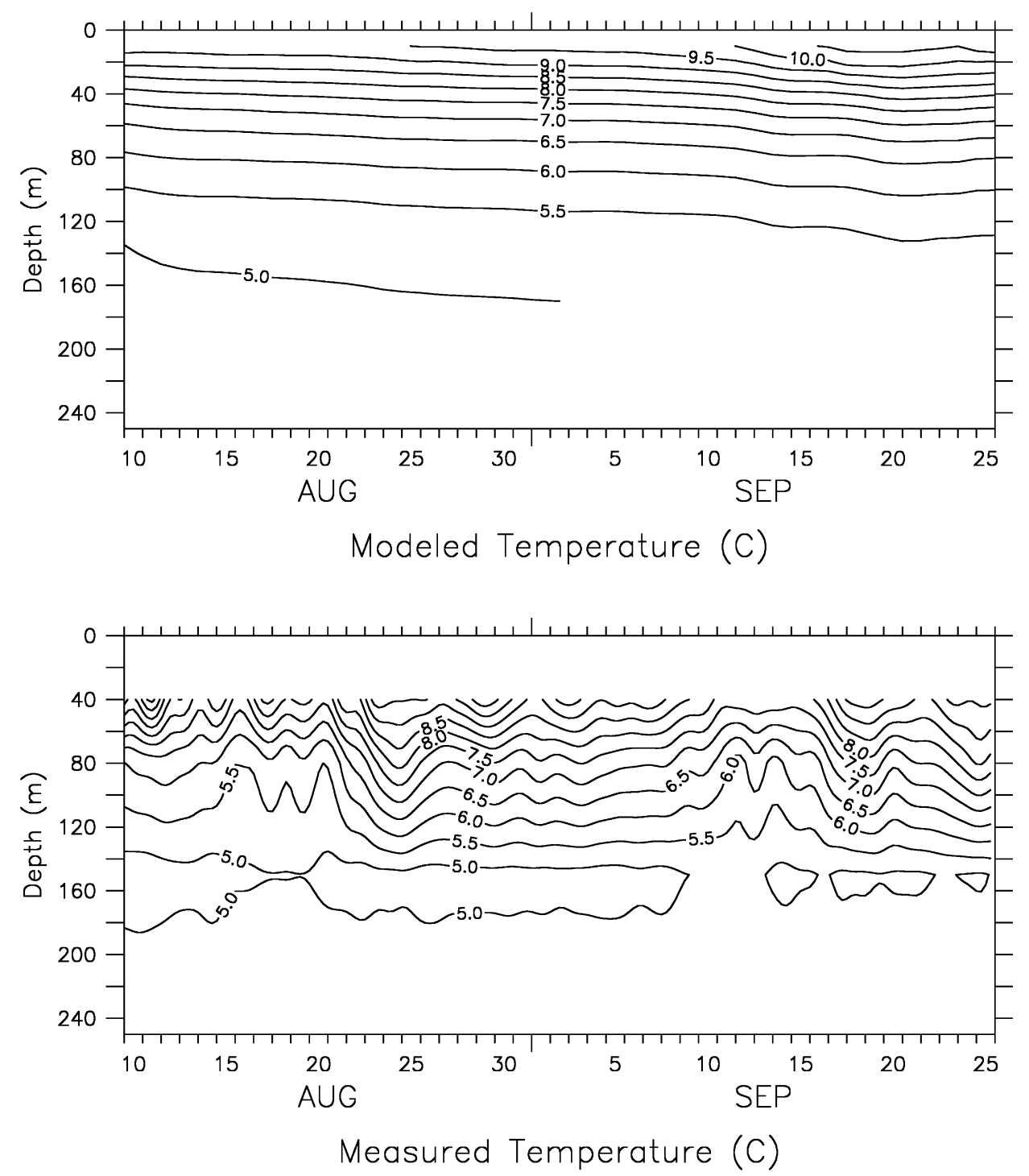

Fig. 13. Time-depth comparison of modeled (upper) and measured (lower) temperature at the center of Shelikof Strait, for August and September 1996.

stability issues. Third, the coarse resolution of the grid, together with its implied viscosity and the proximity of the no-slip boundaries, may artificially retard the flow.

Despite these limitations, a comparison of time-mean vertical profiles, averaged over 3 August-26 September 1996 (Fig. 15), reveals similar vertical shears in both model and data, with a reversal from downstrait (southwestward) to up-strait (northeastward) velocity at $\sim 160 \mathrm{~m}$ in each case. As in Fig. 14, the data exhibit stronger mean down-strait (that is, negative along-shelf) flow than the model.

4.2.3.5. Drogued drifter tracks Model floats were released at locations corresponding to drogued drifter data on DOY 238 (26 August), 1996 (Fig. 16). In the data, the drifter furthest offshore did not lie in the 

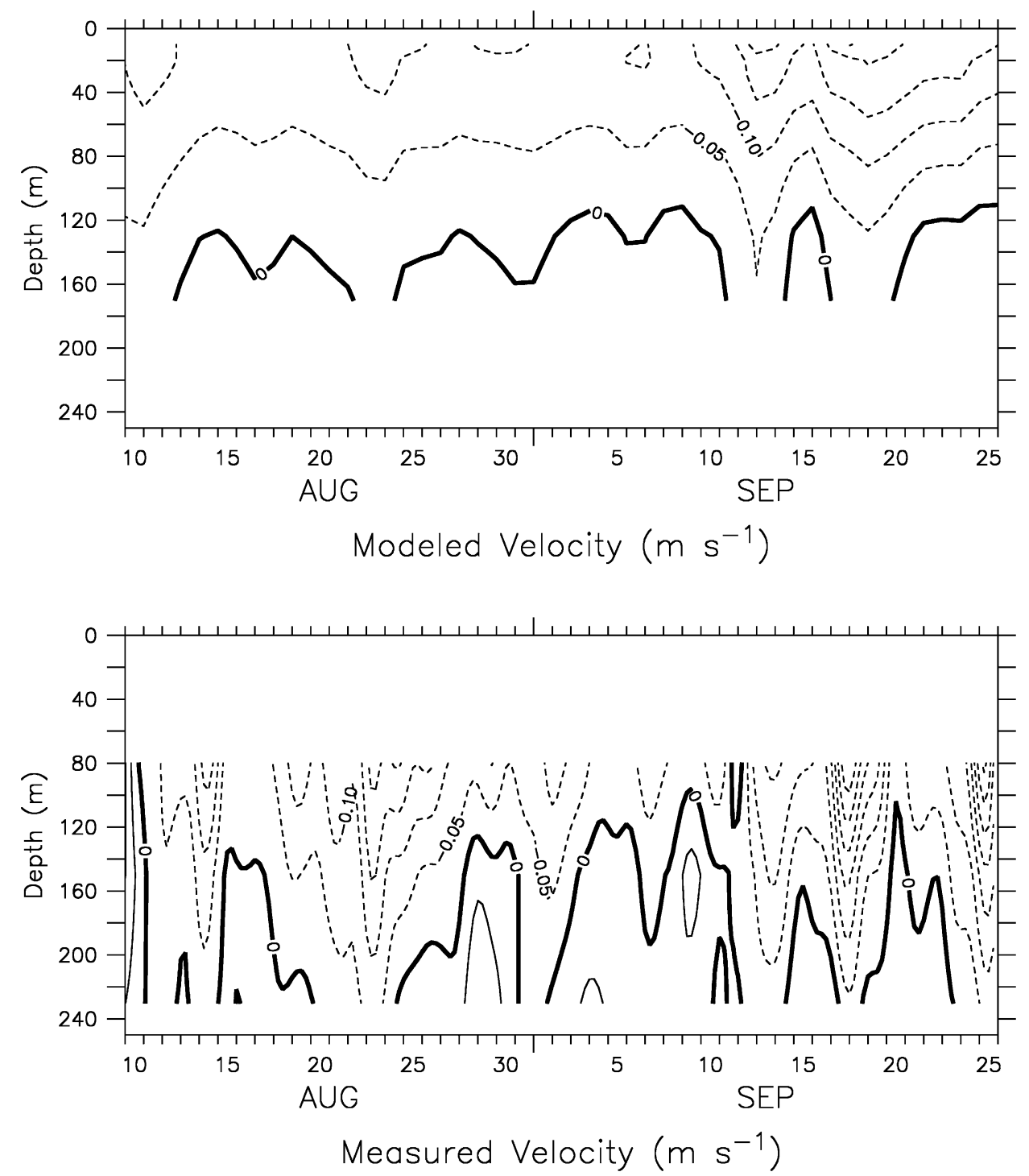

Fig. 14. As Fig. 13 for alongshelf velocities. Negative velocities are to the southwest.

Alaskan Stream, whereas the corresponding model float was vigorously advected by the model Stream. Conversely, one of the mid-shelf drifters was ultimately entrained into the Stream, whereas the corresponding model float was not. Such differences are expected, as the precise location of the stream varies because of eddy activity. Note, however, that the ultimate speeds of real versus model floats entrained in the stream are very similar. A second mid-shelf drifter was observed to drift towards the coast over the 60-day period; the model float executes a similar onshore path after encountering an eddy, but achieves landfall further to the southwest. A nearshore drifter followed a sinuous path through the Shumagin Islands; the corresponding model float remained close to its release point. Again, a divergence of actual versus model paths is expected as a result of the variable nature of the circulation and the inability of this model (or any other, absent extensive data assimilation) to reproduce all the spatial details. 


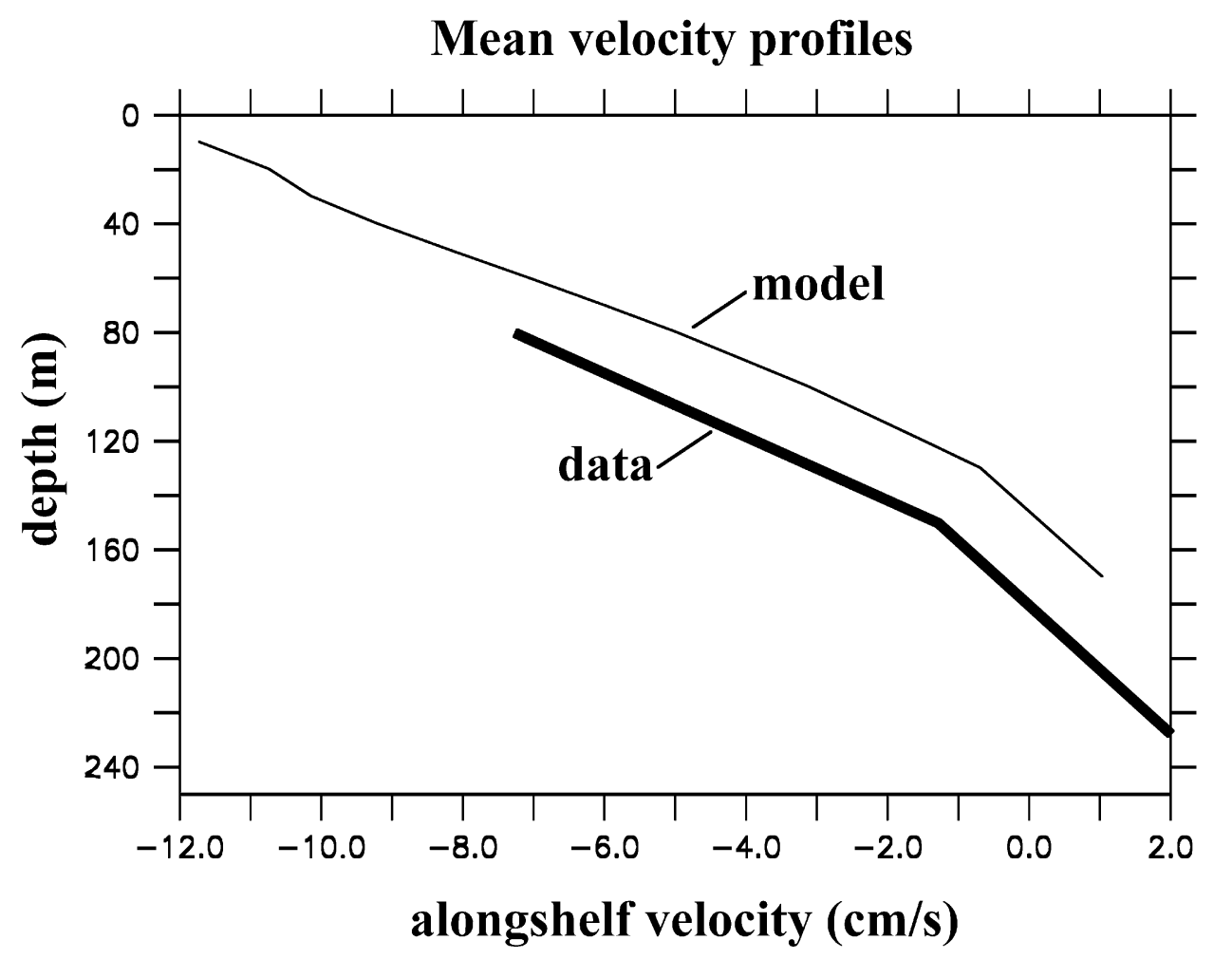

Fig. 15. Time averaged velocity profiles for the data shown in Fig. 14.

4.2.3.6. Sea surface heights Model SSH has been compared with TOPEX/POSEIDON/ERS-2 analyses for 8 October 1996 (Fig. 17), obtained from the web site maintained by the Colorado Center for Astrodynamics Research (CCAR) at the University of Colorado (R. Leben, 2001, personal communication). These results must be viewed with caution, as the TOPEX analysis is designed primarily to capture mesoscale time variability of SSH about its climatological mean, and not its absolute magnitude. Since we do not have a suitable climatology from the model to subtract off the total signal, we have plotted the TOPEX result from CCAR, including their estimate of dynamic height (obtained via climatological hydrographic data), referenced to $1500 \mathrm{~m}$. Similar spatial scales $(\sim 200 \mathrm{~km})$ are apparent for much of the mesoscale energy in both model and data. Both model and data exhibit the same broad depression associated with the Subarctic Gyre. The TOPEX image exhibits many closed eddies in the interior; the model exhibits fewer such closed features, but many strong meanders. Overall, there is less mesoscale energy in the model output than in the data. As noted earlier, the largest mesoscale feature in the model is a large, anticyclonic eddy near Sitka, AK. A smaller feature is present in the data, between 56 and $57^{\circ} \mathrm{N}$ at $\sim 138^{\circ} \mathrm{W}$; it is unclear whether or not this corresponds to any Sitka eddy feature actually present. Indeed, there may be particular difficulties in capturing a stationary eddy feature with mesoscale TOPEX data, as much of the eddy signature would end up in the climatological background. There is some evidence for offshore migration of the Sitka eddy, however, from model studies (e.g. Melsom et al., 1999), and the smaller feature in the data may be the result of that migration. It is presently unknown whether the larger eddy in the data, at $54.5^{\circ} \mathrm{N}, 137^{\circ} \mathrm{W}$, itself corresponds to an offshore migration of the Sitka eddy, or to an eddy formed at some other location. 

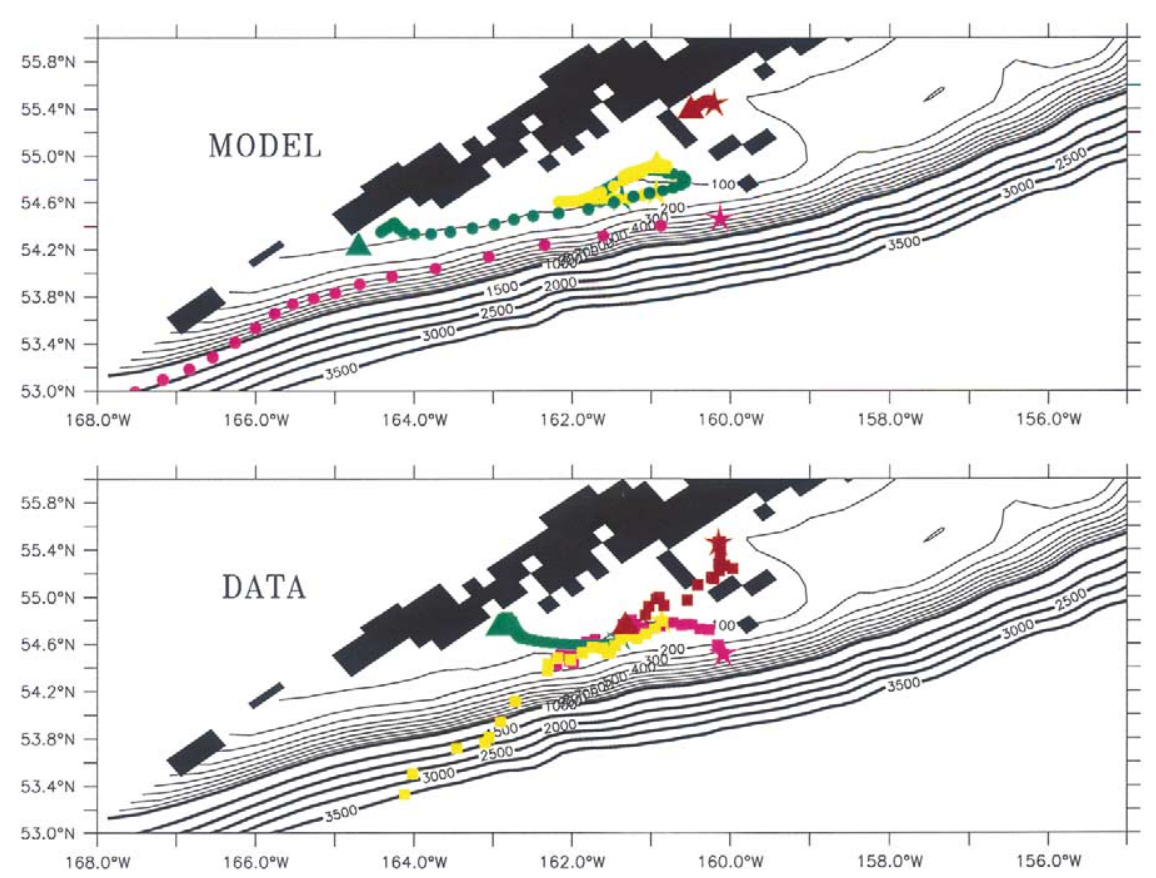

Fig. 16. Comparison of modeled (top) and measured (bottom) drogued drifter tracks at $40 \mathrm{~m}$ depth near the Shumagin Islands. Stars mark track beginning and triangles mark track end.

4.2.3.7. Time series of sea surface height Raw surface elevation data from a tide gauge at Sitka, Alaska were filtered with successive applications of simple 24-h and 25-h moving averages, and corrected for atmospheric pressure using data from a nearby weather station, to reveal the sub-tidal signal. This series was compared with the corresponding free surface elevation data from model runs, both with and without tidal and sub-tidal nudging from the global model (Fig. 18). As with the TOPEX spatial comparison above, the amplitude of the model time series was typically weaker than the amplitude of the data, but the timing of specific events was nonetheless well-reproduced, especially the events of 10-11, 17-18, and 25-26 September. Note that the event of 17-18 September, in particular, appears in both model and data for the velocity series from Shelikof Strait (see Fig. 14).

\subsection{Sensitivity of the regional model to remote barotropic influence}

Although sub-tidal velocity information provided by the global model can be expected to influence the regional model most strongly near the sub-tidal nudging band, dynamics including coastal trapped waves (CTWs), Rossby waves, simple advection, and diffusion can be expected to carry boundary information into the interior, as well. Indeed, one strong motivation for using global model results (or real data) at the boundary of the regional model is to provide just such information about remotely forced CTWs to the regional model interior.

A Hovmuller (distance versus time) plot of the difference in coastal sea level between experiments $2 \mathrm{a}$ and 2c (the sub-tidally 'forced'-i.e. nudged—and 'unforced' regional runs) (Fig. 19) illustrates the propagation of 10-day period signals from the southern nudging band into the interior of the model as CTWs, with a phase speed of $\sim 1000 \mathrm{~km} \mathrm{~d}^{-1}$. This value is somewhat higher than phase speeds calculated for CTWs off Washington and Oregon ( $500 \mathrm{~km} \mathrm{~d}^{-1}$, e.g. Battisti \& Hickey, 1984), and also higher than phase speeds calculated for coastal propagation in SEOM itself $\left(\sim 100-200 \mathrm{~km} \mathrm{~d}^{-1}\right)$. Given the higher 
(a)

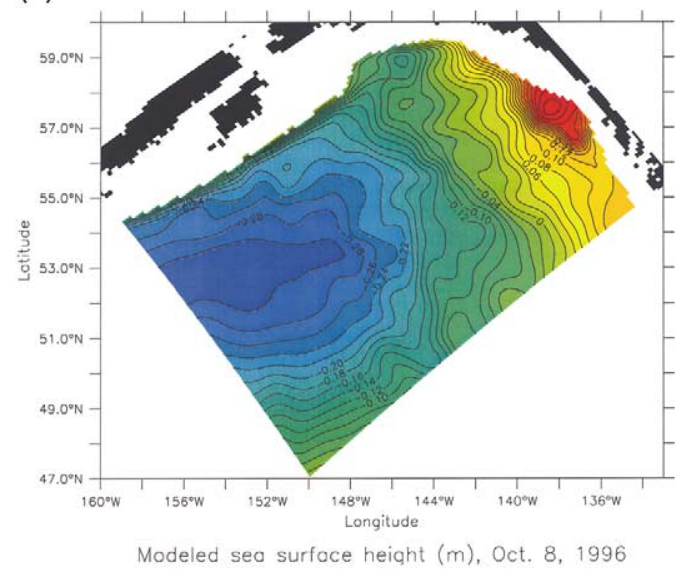

(b)

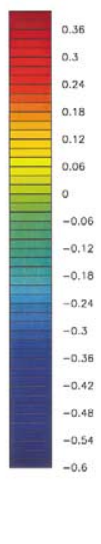

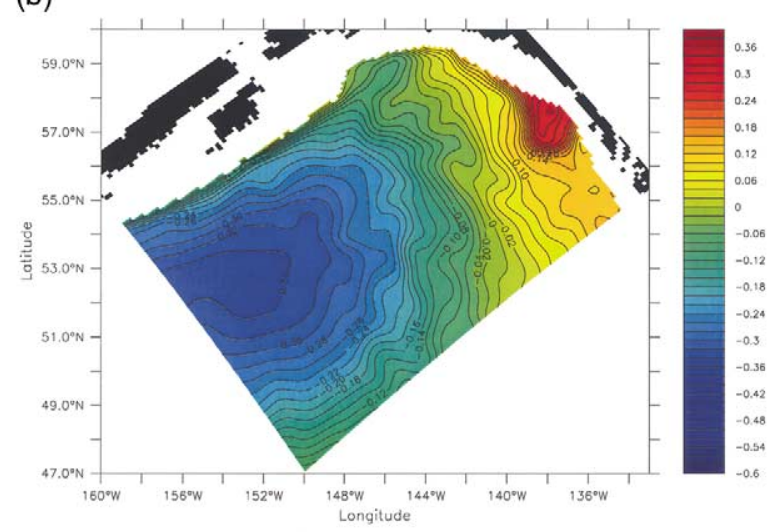

Modeled sea surface height $(m)$ without subtidal influence, Oct. 8,1996

(c)

TOPEX/ERS Analysis Oct 91996

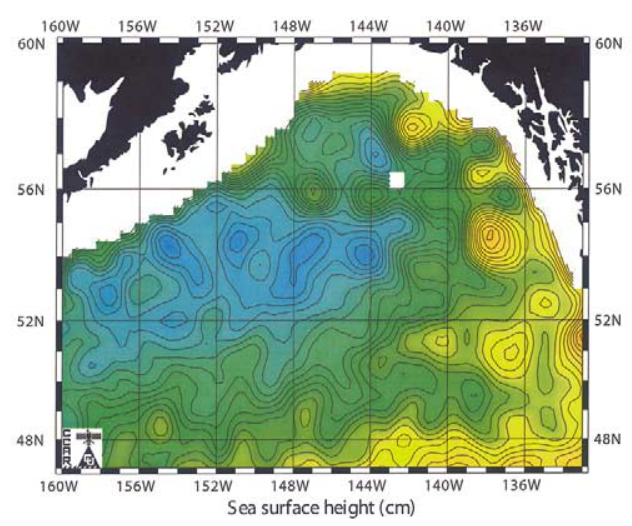

Fig. 17. Comparison of model SSH with observed SSH from TOPEX/ERS, for 28 October 1996. TOPEX estimate includes climatological dynamic height, referenced to $1500 \mathrm{~m}$. (a) Model results with barotropic (tidal and sub-tidal) boundary forcing; (b) model results without barotropic boundary forcing; (c) TOPEX data.

latitude of our region, and its steep, irregular topography, a closer match with lower latitude data is not expected. A different phase speed in the regional model, relative to the global model, is also expected, insofar as the global model uses bathymetry quite different from the regional model.

To reveal more explicitly the influence of the barotropic nudging, snapshots of SST, surface velocity, SSH and depth-averaged velocity are presented for the 'unforced' run (run 2c), and the run with sub-tidal forcing only (run 2a) (Fig. 20). Also presented are difference maps representing the effects of sub-tidal forcing ('sub-tidal only' run minus 'unforced' run) and the effects of tidal forcing ('sub-tidal and tidal' run minus 'sub-tidal only' run) (Fig. 21). Note that climatological $\mathrm{T}$ and $\mathrm{S}$ are used as a boundary condition in all these runs; hence, the differences reflect only the addition of our particular forms of barotropic information. First, note how the sub-tidally forced runs exhibit higher sea levels in the interior (and hence lower sea levels at the coast, relative to the interior), compared to the unforced run. Both surface and barotropic velocity differences indicate that information from the global model has slightly weakened the coastal flows, yielding an underestimate (by 20\%) of near-surface flows at the location of current meter mooring in Shelikof Strait. This may be because in coastal areas, barotropic velocities from the global 


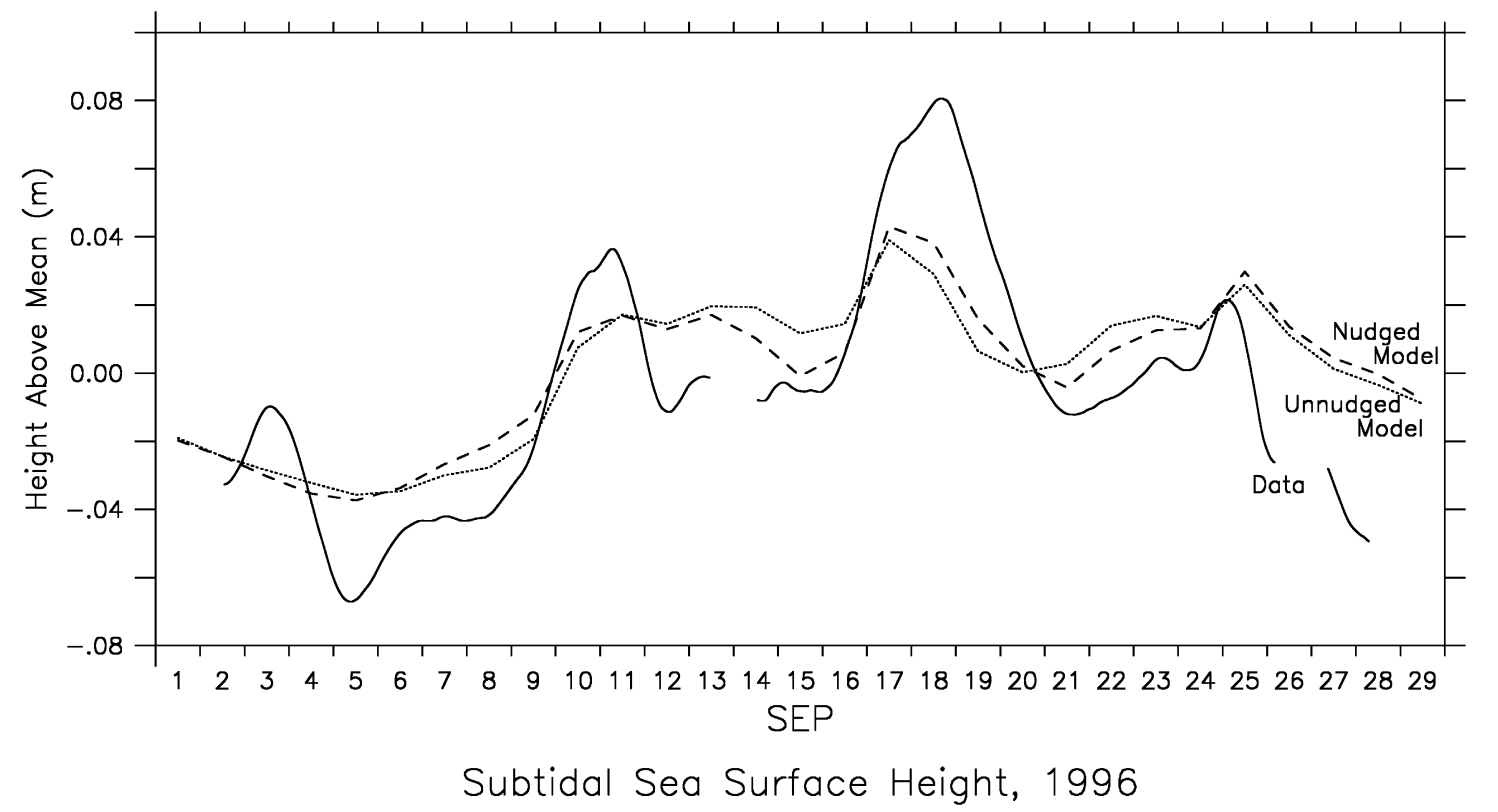

Fig. 18. Sub-tidal sea surface height at a tide gauge at Sitka, AK (solid line) (corrected for local atmospheric pressure), compared with corresponding signals from model runs with (dashed line) and without (dotted line) nudging of global velocity data. In each case, the time mean for this interval has been subtracted from the time series.

model (Figs. 5 and 6) are generally weaker than those produced by the regional model (Fig. 8), largely as a result of the deeper bathymetry used by the global model.

Second, note that the addition of the sub-tidal barotropic information has significantly modified both surface and barotropic velocity patterns, and the SST, by altering the positions of interior eddies. In many locations these differences are as large as $0.2 \mathrm{~m} \mathrm{~s}^{-1}$ and $1{ }^{\circ} \mathrm{C}$, respectively.

Finally, note how the sub-tidal signals have in fact added mesoscale variability to the interior. Mesoscale eddies and meanders in the SSH field are in fact more numerous, and of greater amplitude, after addition of the sub-tidal boundary information (compare Figs. 17a and b). In particular, note the two closed eddy features in the northern GOA $\left(57-59^{\circ} \mathrm{N}, 144-146^{\circ} \mathrm{W}\right)$, produced when sub-tidal forcing is added. The time variance in SSH was also calculated, for the period 13 September-13 October. Averaged over the areas shown in Fig. 17, this approximate measure of Eddy Kinetic Energy was $~ 28 \%$ higher in the subtidally-forced case, as compared with the unforced case.

The addition of tides to the sub-tidally forced run does not make any substantial difference to the results in most areas. However, a significant impact is observed in shallow areas around Kodiak Island and Cook Inlet, where the strongest tides have been observed. In those areas, SST is modified by $\sim 1{ }^{\circ} \mathrm{C}$ and surface currents are modified in geostrophic response to those changes in the scalar fields. The barotropic subtidal velocities are slightly altered, possibly representing a weak tidal residual.

Time series of SSH at the Sitka tide gauge are shown for these sensitivity experiments (Fig. 18). The model run with sub-tidal and tidal barotropic forcing produced a time series with slightly stronger amplitude than the run without either of those influences, in conformity with the SSH snapshot results. A run with sub-tidal, but no tidal, forcing produced a time series indistinguishable from that of the sub-tidal-plustidally forced run. Apparently, the addition of barotropic sub-tidal information adds variance to the time series of SSH (and improves the overall fit with observations), just as it appears to add spatial variance to the SSH pattern. 


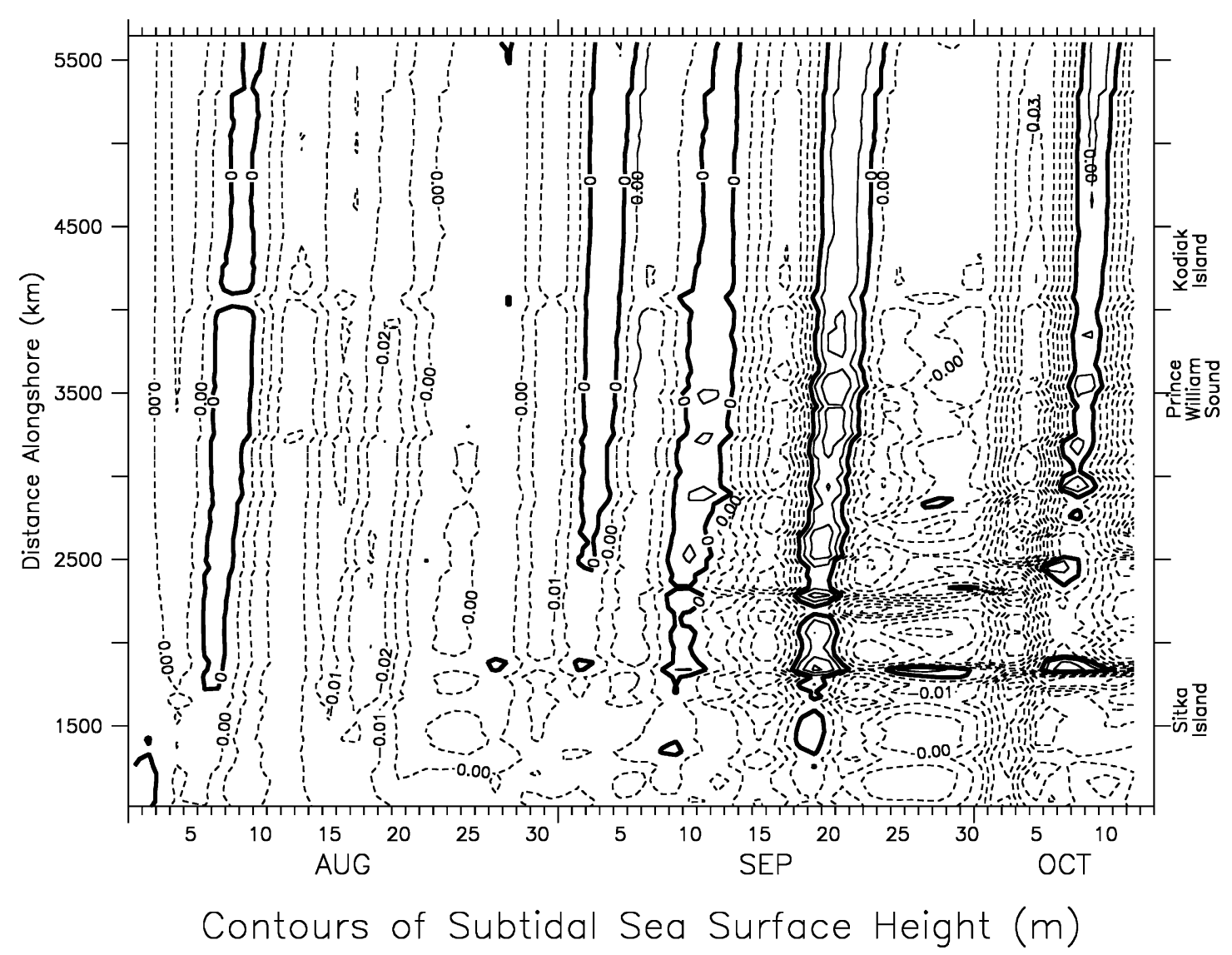

Fig. 19. Hovmuller diagram (distance versus time) for the difference in sea surface height (m) produced by boundary nudging to global model sub-tidal velocities.

\section{Discussion and conclusions}

No ocean model without extensive data assimilation is capable of replicating all the details of the true ocean, even at the mesoscale. Here, we have nudged information as a boundary condition over limited areas, using global model results (as opposed to measured information). Hence, the best we can hope to achieve is to replicate time-mean features of the flow, and to aspire to capture some, but not all, of the time variability at any location (i.e. 'statistically correct' fields). With these caveats, our initial experiments with various configurations of two circulation models for the Gulf of Alaska suggest that this area can be realistically modeled using a regional scale model. Our regional model with $\sim 13-20 \mathrm{~km}$ horizontal resolution and 20 vertical s-coordinate levels captures much of the spatial and seasonal pattern of CGOA circulation. Both the AC-AS and ACC current systems are easily identified in model output. The model also captures the dominant $200 \mathrm{~km}$ scale variability observed in the Gulf. It displays especially strong mesoscale dynamics in the vicinity of the Sitka eddy. Many observed SST patterns are reproduced, with gradients somewhat larger than observed. Additional runs (not shown here) have reproduced the seasonal weakening/strengthening of the coastal current in the CGOA over a full model year.

Interannual differences have also been evident between different years simulated; for instance, spring 1997 has generally higher SST than spring 1995, as was observed in the CGOA at Shelikof Strait (J. 


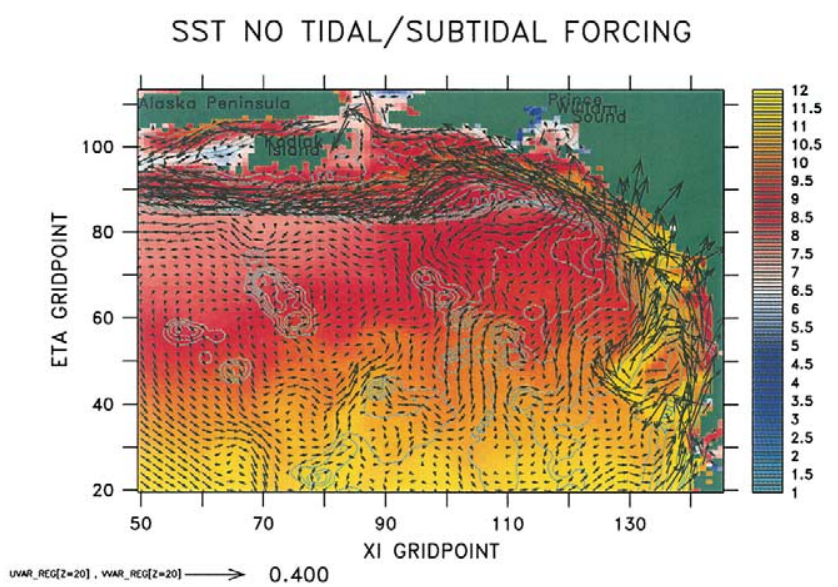

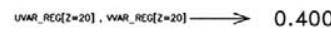

SSH NO TIDAL/SUBTIDAL FORCING

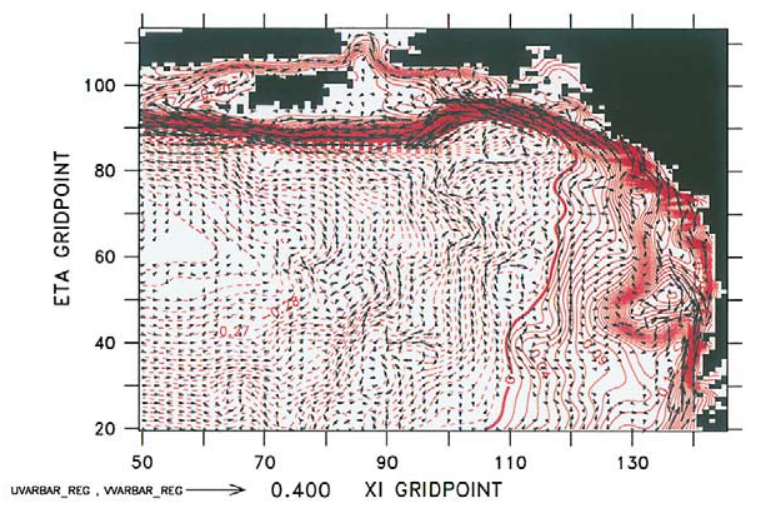

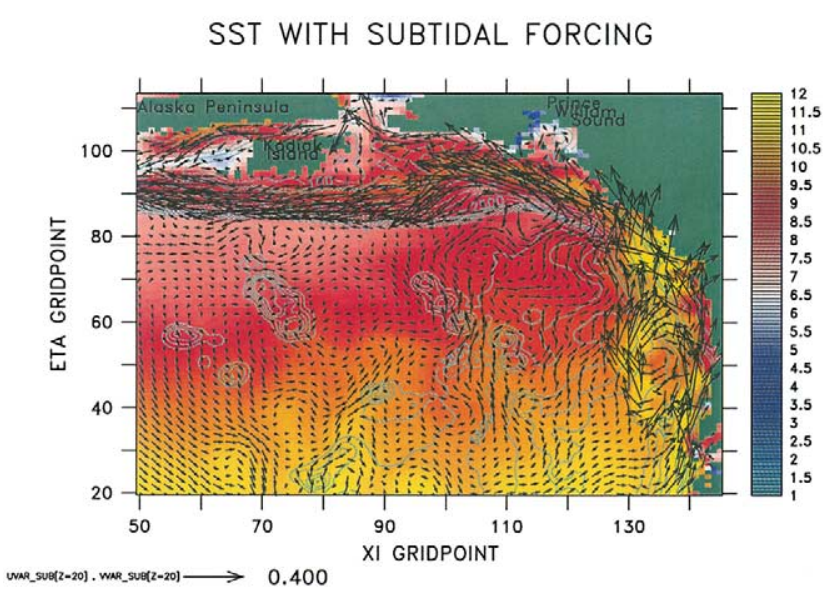

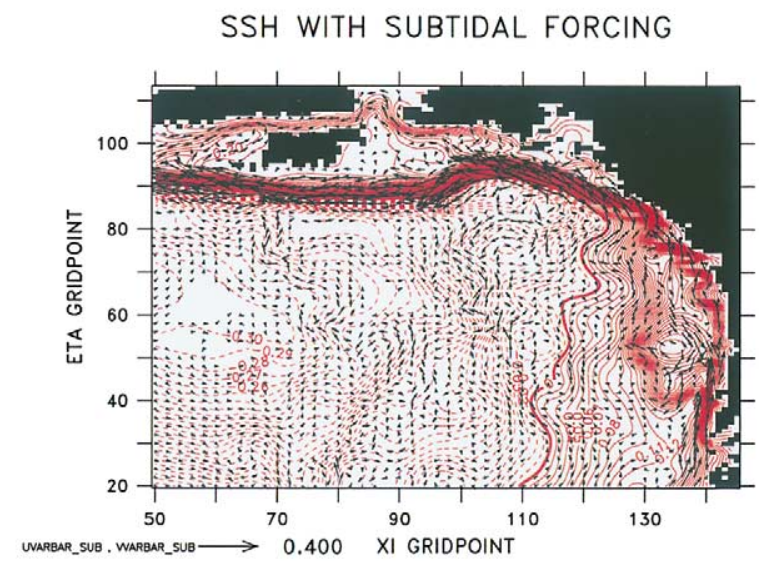

Fig. 20. Results as in Figs. 7 and 8 for model runs with no tidal or sub-tidal barotropic nudging (upper) and sub-tidal barotropic nudging only (lower). SST $\left({ }^{\circ} \mathrm{C}\right)$ and surface velocity $\left(\mathrm{m} \mathrm{s}^{-1}\right)$ are on left, SSH $(\mathrm{m})$ and barotropic velocity $\left(\mathrm{m} \mathrm{s}^{-1}\right)$ are on right.

Schumacher, personal communication). This is important because it implies that by using this model, we will be able to investigate effects of the physical regime shift that has been documented in the GOA system.

We have also found that both tidal and sub-tidal barotropic information from a global model can be effectively incorporated into the regional model as a boundary condition, through the use of suitably designed nudging bands located outside the region of interest. Spurious effects of rigid wall dynamics are avoided by allowing free compensatory flow in the telescoped region outside the sub-tidal nudging band. A proper choice of nudging coefficients minimizes the interference between the applied tidal and subtidal signals.

Model results are affected, in a specific and limited manner, by the inclusion of barotropic boundary information from the global model. We find the regional model, with or without barotropic boundary forcing, generates appropriate current systems (AS, ACC) and scalar fields, but with less spatial (mesoscale) variability of sub-tidal SSH than is observed, and also with less temporal (e.g. daily-to-weekly) variability of sub-tidal currents and SSH than is observed. Barotropic sub-tidal information from the global model 

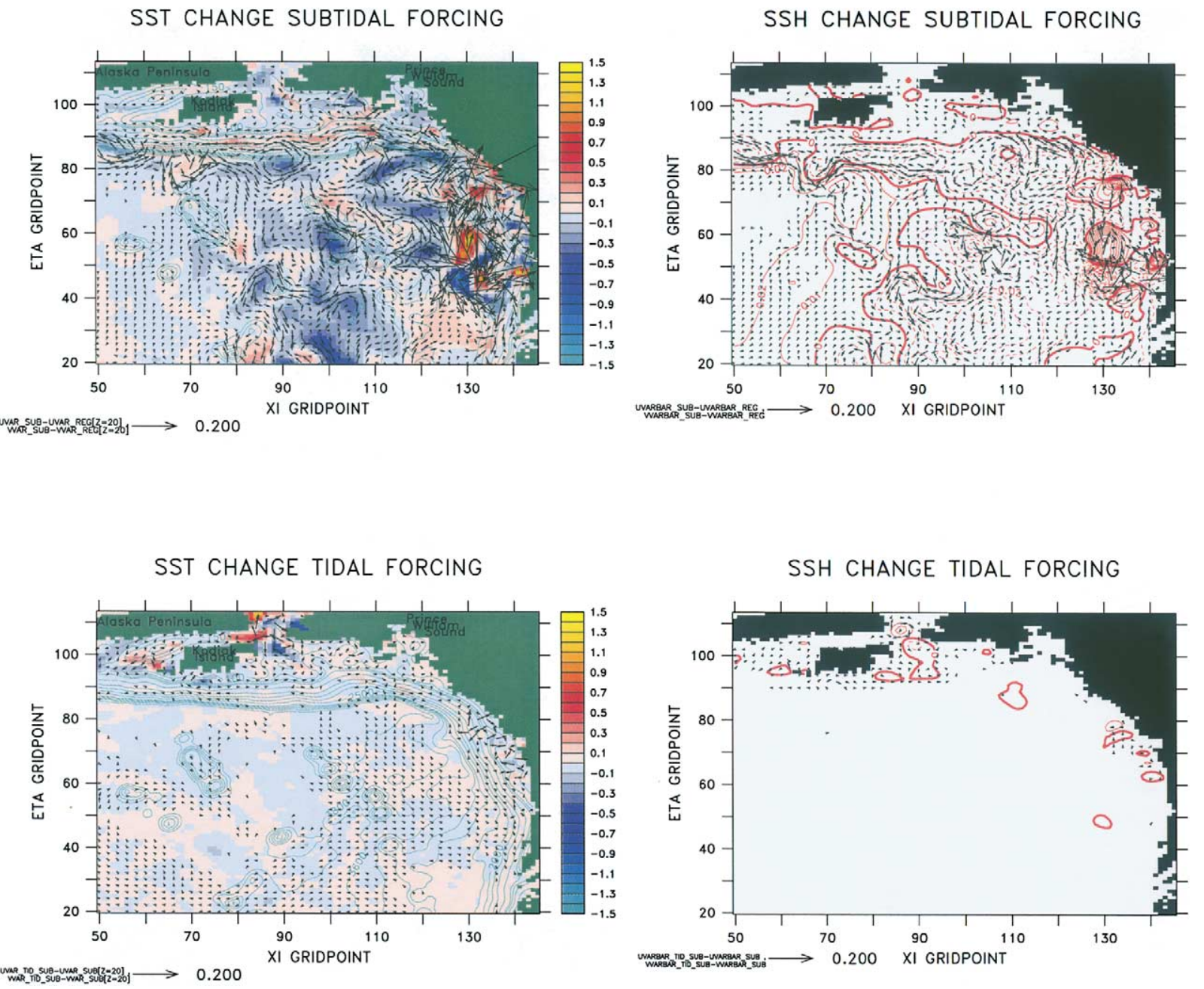

Fig. 21. Difference in velocity and temperature fields between: model with sub-tidal barotropic nudging versus model with no subtidal barotropic nudging (upper); model with sub-tidal and tidal barotropic nudging versus model with sub-tidal nudging only (lower). Layout and variables as in Fig. 20. Note different length scale for vectors, relative to Fig. 20.

penetrates the regional model interior, enhancing the spatial and temporal variability in most (but not all) areas, and modifying regional velocities and scalar fields (both surface and subsurface) in both shallow and deep areas. Barotropic tidal information exerts a significant influence on sub-tidal scalar and velocity structure only in specific shallow areas, where the tides (and tidal mixing) are strongest. Pending the exploration of alternate coupling schemes, we infer from these results that on a time scale of months, purely barotropic information from outside the CGOA will have a modest impact on its mean regional circulation, but a potentially stronger impact on the statistics and details of mesoscale features.

These results are an important step towards our goal of exploring the effect that interannual and decadal changes in GOA circulation have on lower trophic level dynamics and fishery populations. However, the true coastal current (that is, the ACC) has a strong baroclinic structure, and the use of only barotropic information may be inadequate to convey remote influences to this structure. Further, the global model bathymetry was typically deeper than the corresponding bathymetry in the regional model; for a strongly 
baroclinic flow, the depth-averaged velocity from the global model might provide an artificially weak signal for the regional model under our present coupling scheme, and so artificially dampen the locally generated baroclinic flows.

It is possible that a larger impact of global barotropic information would be observed with one or more of the following changes: (1) the barotropic velocity used to nudge the regional model could be adjusted to account for differences in underlying bathymetry between global and regional models (i.e. we could nudge to the value of barotropic transport produced by the global model, rather than to the value of barotropic current). Note, however, that this may lead to overestimates of the remote influence on coastal areas, just as the present method may underestimate that influence; (2) the nudging constant could be increased, or the nudging bands could be expanded more fully to spin-up wave signals for propagation into the interior. Note, however, that the former approach may create a strong barrier to the free passage of internally generated signals out of the regional model domain; (3) the tidal and sub-tidal nudging bands could be further separated, to guard against any possible interference between tidal nudging and subtidal nudging.

Future studies will explore these issues in more detail, as we gain more experience with both barotropic and baroclinic coupling methods. We believe that our model results can be further improved relative to data by including the influence of baroclinic information from the global model. Specifically, we plan to generate multiyear simulations with the global layered model, and project information about the first baroclinic mode from those results onto the first baroclinic mode of the regional model in the sub-tidal nudging band. Intensification of current speeds to more closely match observed current magnitudes and spatial focus of the AS, AC and ACC will also require even higher horizontal resolution in the regional model and ageostrophic wind forcing. New regional model codes, which take advantage of parallel computer architectures, will allow higher resolutions to be implemented for our multiyear runs in GLOBEC. New studies to generate and compare fine-scale winds with NCEP products in the CGOA are also now underway in GLOBEC.

\section{Acknowledgements}

This research is contribution 2174 from NOAA/Pacific Marine Environmental Laboratory and contribution FOCI-0387 to NOAA's Fisheries Oceanography Coordinated Investigations, and was supported by the Joint Institute for the study of the Atmosphere and the Oceans under cooperative agreement NA67RJ0155, contribution \#750. This is contribution number 202 of the US GLOBEC program, jointly funded by the National Science Foundation and National Oceanic and Atmospheric Administration. AJH and DBH are supported by GLOBEC under NSF OCE-96-18553 and OCE-97-11329. Support for the development of the layered version of SEOM was also provided by NSF (ACR-9814651). DBH gratefully acknowledges the hospitality and financial support of the Miller Institute for Basic Research in Science received during a sabbatical visit to the University of California, Berkeley. Support from the Arctic Region Supercomputing Center is also gratefully acknowledged. We also thank Ted Strub and Corrine James, for their assistance with Pathfinder SST data.

\section{Appendix A}

\section{The global model}

A large scale context for our regional studies is provided by simulations with the Spectral Element Ocean Model (SEOM; Haidvogel \& Beckmann, 1999; Iskandarani, personal communication). SEOM has 
been developed for the purpose of high resolution basin scale modeling on unstructured global grids (Iskandarani et al., 1994). The governing equations are the $3 \mathrm{D}$, Reynolds averaged, Navier Stokes equations with Boussinesq and hydrostatic assumptions. Lateral subgridscale mixing of momentum is parameterized using the shear and mesh size dependent formulation of Smagorinsky (1963), which has proven to be highly effective on these horizontally heterogeneous grids. The resulting class of large scale circulation models has several significant virtues over those using more traditional approaches, including complete geometric flexibility, regionally selective horizontal resolution, and the ability to avoid open boundary conditions by use of global grid refinement.

The spectral element circulation model has now been applied in its reduced gravity form to a variety of test problems and global oceanic/atmospheric applications. When applied to a now standard suite of shallow water test problems on the sphere, SEOM is shown to be highly competitive with other numerical models, including those based on spherical harmonic methods (Taylor, Tribbia, \& Iskandarani, 1997). Oceanic applications on global, non uniform grids show that these favorable properties are maintained in the presence of continental geometry and highly unstructured elemental meshes (Haidvogel, Curchitser, Iskandarani, Hugjes, \& Taylor, 1996).

Here, for economy, SEOM has been implemented on a global grid in layered form with a total of five isopycnal layers (Fig. 2). Vertical transfer of momentum is represented with weak (linear) interfacial drag and (nonlinear) stress laws. Following Hurlburt, Wallcraft, Schmitz, Hogan, and Metzger (1996), outcropping of the layers is avoided by mass sharing between layers as a minimum 'entrainment thickness', here taken to be $40 \mathrm{~m}$, is reached. Table A1 gives the relevant parameters (resting layer thicknesses and reduced gravities) used in the global simulation. A significant limitation of the non-outcropping layered model is that topographic variations must be contained within the lowermost layer. We have done so here by clipping topography (obtained from ETOP05) at $200 \mathrm{~m}$ (minimum) and $5000 \mathrm{~m}$ (maximum), and then multiplying the resulting topographic excursions above $5000 \mathrm{~m}$ by 0.85 . Some of the effects of this topographic shrinkage are noted in the main body of the text.

As a first test of behavior, the global layered model has been forced with a repeating cycle of NCEP winds, corresponding to the period of NSCAT wind availability (August 1996 through July 1997). A comparable simulation using NSCAT winds has also been prepared, as a basis for a future sensitivity study. No explicit thermodynamic forcing is included; therefore, the resulting simulations can at most represent the wind driven component of the large scale, low frequency circulation.

SEOM is highly scalable on parallel computing platforms (Curchitser, Iskandarani, \& Haidvogel, 1998). The simulations reported in the text have been obtained on a Beowulf type cluster of Sun Ultra 5 workstations maintained at the Institute of Marine and Coastal Sciences, Rutgers University. On this system, a year's simulation requires approximately $6 \mathrm{CPU}$ days when run on 12 processors.

Table A1

Mean interface depths $(\mathrm{m})$ and reduced gravity at interfaces $\left(\mathrm{m} \mathrm{s}^{-2}\right)$ for the layered implementation of the Spectral Element Ocean Model

\begin{tabular}{ll} 
Interface depth, m & Gravity \\
\hline 0 & 9.81 \\
135 & 0.020 \\
320 & 0.009 \\
550 & 0.004 \\
800 & 0.002
\end{tabular}




\section{Appendix B}

\section{The regional model}

For regional circulation in the CGOA, we employed the S-Coordinate Rutgers University Model (SCRUM) of Song and Haidvogel (1994). We implemented the model on a rectilinear grid oriented at $38^{\circ}$ to true north. The horizontal grid has telescoped edges to reduce the computational overhead associated with horizontal boundary conditions. The grid has 145 by 113 horizontal gridpoints with 17 telescoped gridpoints on the southern and western boundaries (Fig. 3). The finely resolved area of the model domain reaches from Queen Charlotte Island in the south to Unimak Pass in the west. The telescoped region continues to the south end of Vancouver Island, and to Amukta Pass in the west. Grid resolution varies from $13-22 \mathrm{~km}$ in the finely resolved area to $200 \mathrm{~km}$ near the western and southern walls. As described in Section 2.2, the telescoped regions here serve primarily to recirculate flows into and out of the area of interest. A no-slip condition is applied at the solid walls.

The model has 20 vertical s-coordinate levels. We optimized the s-coordinate feature of SCRUM to achieve quasi uniform spacing near the surface. In the shallowest $(50 \mathrm{~m})$ areas, spacing is uniformly 2.5 $\mathrm{m}$ over the entire water column. In the deepest $(4000 \mathrm{~m})$ areas, spacing is $3.6-10.0 \mathrm{~m}$ over the top $50 \mathrm{~m}$ of the water column, with closest spacing nearest the surface. This quasi-uniform spacing will facilitate efficient coupling with the biological models.

SCRUM is written in highly vectorized code, and most of the simulations were obtained on vector architectures (CRAY J932) at the Arctic Region Supercomputing Center. However, recent simulations have been obtained on an equally fast, single-processor (Alpha XP-1000) workstation at PMEL. On the CRAY platform, simulation of one model year requires approximately 7 CPU days; on the local workstation, 5 CPU days are required.

\section{Bathymetry}

Model bathymetry was interpolated from a specially developed 5 minute bathymetric map of the CGOA, based on ETOPO5 and other sources. While ETOPO5 has the advantage of broad coverage, it is well known to be inaccurate in many coastal areas. More accurate bathymetric data were obtained from two different sources and used to improve ETOPO5. Nearshore data were derived from the National Ocean Service (NOS) Hydrographic Data Base, error checked and gridded to 30 seconds by National Geophysical Data Center (NGDC) and distributed as the TerrainBase data collection. These data are focused on specific coastal areas such as Cook Inlet. Offshore data were derived from Smith and Sandwell (1997), who collected and verified coastline and marine ship track data from many sources, and distributed those data as part of their 2 minute measured and estimated digital topographic map. Though their estimated bathymetry (based partly on gravity anomalies) contains too much noise to be useful on the continental shelf, the measured bathymetry was easily extracted and used to improve ETOPO5 values offshore.

Data from these two detailed sources were combined and interpolated to a 5 minute grid using Global Mapping Tools (GMT). To reduce computational effort, the interpolations were done for $10^{\circ} \times 10^{\circ}$ areas that overlap by $0.25^{\circ}$. The interpolated grid points match those of ETOPO5 so that when they were combined, ETOPO5 seamlessly supplied data in areas where the detailed bathymetry data set was lacking. The final bathymetry is particularly accurate in areas of high data resolution, such as along the shelf break. It constitutes a major improvement over ETOPO5, especially in shallow shelf areas such as the Trinity Banks southwest of Kodiak Island. After interpolation to the SCRUM grid, the bathymetry was cropped to $50 \mathrm{~m}$ (minimum) and $4000 \mathrm{~m}$ (maximum), and filtered with six passes of a Shapiro filter, to improve numerical stability of the model. The result is shown in Fig. 4. Even after filtering, the result is considerably more accurate than ETOPO5 alone. 


\section{Heat flux and wind stress}

Suitable values of wind and heat flux in specific years were obtained from the NCEP/NCAR Global Reanalysis Project. NCEP products include a global data set of atmospheric variables, obtained by combining a global spectral model with historical data. Their model has been run for the years since 1958, and the output is available online. Resolution of these data is roughly $2^{\circ}$. Temporal resolution is $6 \mathrm{~h}$, but we have chosen to use daily averages as input to our regional circulation model.

Daily average NCEP/NCAR values for latent and sensible heat net flux, and net longwave and shortwave radiation were summed to provide total heat flux from the ocean. Daily average $\mathrm{U}$ wind and $\mathrm{V}$ wind at $10 \mathrm{~m}$ height above the ocean surface were converted to wind stress using the simple formula:

$$
\tau=\rho_{\mathrm{a}} C_{\mathrm{d}} U 10|U 10|
$$

where $\tau$ is the wind stress in $\mathrm{N} \mathrm{m}^{-2}$, $\mathrm{U} 10$ is the vector of wind speed in $\mathrm{m} \mathrm{s}^{-1}, \rho_{a}$ is the air density and $C_{\mathrm{d}}=0.0012$.

\section{Freshwater input}

Salinity controls the density field more strongly than temperature for much of the year in the CGOA; freshwater input is greatest in October and smallest in March (Royer, 1982), and is primarily from distributed sources. Monthly values of integrated freshwater runoff along segments of the coastline were derived by Royer (1982) (and pers. comm.) from snowpack, precipitation and temperature data. The data represent runoff from areas seaward of the coastal mountain range. To supplement this estimate with freshwater contribution from inland areas, we utilized Copper and Suisitna River discharge data from the US Geological Survey (USGS). Because there are few complete years of data, a monthly climatology was computed for each river using all the available data. These large rivers supply a small amount of freshwater $(\sim 10 \%$ of the total), relative to the line sources ( $\sim 90 \%$ of the total), but their peak discharge is earlier in the year.

\section{Mixing}

Vertical mixing is parameterized as a function of local shear and stability, using Mellor Yamada level 2.0 closure (Mellor \& Yamada, 1974). Background diffusivity and viscosity were $10^{-4}$ and $10^{-3} \mathrm{~m}^{2} \mathrm{~s}^{-1}$, respectively. Horizontal mixing of both scalars and momentum is calculated with a biharmonic operator, and scaled by the local grid spacing as described in Hermann and Stabeno (1996). Mixing is computed along geopotential surfaces, rather than along sigma surfaces (Haidvogel \& Beckmann, 1999).

\section{References}

Battisti, D. S., \& Hickey, B. M. (1984). Application of remote wind-forced coastal trapped wave theory to the Oregon and Washington coasts. Journal of Physical Oceanography, 14, 887-903.

Bhaskaran, S., Lagerloef, G. S. E., Born, G. H., Emery, W. J., \& Leben, R. R. (1993). Variability in the Gulf of Alaska from Geosat altimetry data. Journal of Geophysical Research, 98, 16311-16330.

Crawford, W. R., \& Whitney, F. A. (1999). Mesoscale eddy aswirl with data in Gulf of Alaska. EOS Transactions of the American Geophysical Union, 80, 365-370.

Curchitser, E. N., Iskandarani, M., \& Haidvogel, D. B. (1998). A spectral element solution of the shallow-water equations on multiprocessor computers. Journal of Atmospheric and Oceanic Technology, 15, 510-521.

Flather, R. A. (1976). A tidal model of the northwest European continental shelf. Memoires de la Societe Royale des Sciences de Leige Ser. 6, 10, 141-164.

Haidvogel, D. B., \& Beckmann, A. (1999). Numerical ocean circulation modeling. Imperial College Press.

Haidvogel, D. B., Curchitser, E., Iskandarani, M., Hughes, R., \& Taylor, M. (1996). Global modeling of the ocean and atmosphere using the spectral element method. Atmosphere-Ocean, 35, 505-531.

Hermann, A. J., \& Stabeno, P. J. (1996). An eddy resolving model of circulation on the western Gulf of Alaska shelf. I. Model development and sensitivity analyses. Journal of Geophysical Research, 101, 1129-1149. 
Hurlburt, H. E., Wallcraft, A. J., Schmitz, W. J. Jr., Hogan, P. J., \& Metzger, E. J. (1996). Dynamics of the Kuroshio/Oyashio current system using eddy-resolving models of the North Pacific Ocean. Journal of Geophysical Research, 101, 941-976.

Iskandarani, M., Haidvogel, D. B., \& Boyd, J. P. (1994). A staggered spectral finite element model for the shallow water equations. International Journal of Numerical Methods in Fluids, 20, 393-414.

Lagerloef, G. S. E. (1995). Interdecadal variations in the Alaskan Gyre. Journal of Physical Oceanography, 25, 2242-2258.

Levitus, S., Burgett, R., \& Boyer, T. P. (1994). World Ocean Atlas 1994, 4 volumes. Washington, DC: NOAA/NESDIS/NODC.

Marchesiello, P., McWilliams, J. C., \& Shchepetkin, A. F. (2001). Open boundary conditions for long-term integration of regional oceanic models. Ocean Modelling, 3, 1-20.

Matthews, P. E., Johnson, M. A., \& O’Brien, J. J. (1992). Observation of mesoscale ocean features in the Northeast Pacific using Geosat radar altimetry data. Journal of Geophysical Research, 97, 17829-17840.

Mellor, G. L., \& Yamada, T. (1974). A hierarchy of turbulence closure models for planetary boundary layers. Journal of Atmospheric Science, 31, 1791-1806.

Melsom, A., Meyers, S. D., Hurlburt, H. E., Metzger, E. J. \& O’Brien, J. J. (1999). ENSO effects on Gulf of Alaska Eddies. Earth Interactions, 3. [Available online at http://EarthInteractions.org].

Musgrave, D. L., Weingartner, T. J., \& Royer, T. C. (1992). Circulation and hydrography in the northwestern Gulf of Alaska. DeepSea Research, 39, 1499-1519.

Mysak, L. A., Muench, R. D., \& Schumacher, J. D. (1981). Baroclinic instability in a downstream varying channel Shelikof Strait, Alaska. Journal of Physical Oceanography, 11, 950-969.

Palma, E. D., \& Matano, R. P. (1998a). On the implementation of passive open boundary conditions for a general circulation model: the barotropic mode. Journal of Geophysical Research, 103, 1319-1341.

Palma, E. D., \& Matano, R. P. (1998b). On the implementation of passive open boundary conditions for a general circulation model: the three-dimensional case. Journal of Geophysical Research, 105, 8605-8627.

Reed, R. K. (1984). Flow of the Alaskan Stream and its variations. Deep-Sea Research, 31, 369-386.

Reed, R. K., \& Schumacher, J. D. (1986). Physical oceanography. In D. W. Hood, \& S. Zimmerman (Eds.), The Gulf of Alaska: physical environment and biological resources (pp. 57-75). Alaska Office, Ocean Assessments Division, NOAA, US Department of Commerce.

Reed, R. K., Schumacher, J. D., \& Wright, C. (1981). On coastal flow in the Northeast Gulf of Alaska near Yakutat. AtmosphereOcean, 19, 47-53.

Reed, R. K., \& Stabeno, P. J. (1993). The recent return of the Alaskan Stream to Near Strait. Journal of Marine Research, $51,515-527$.

Royer, T. C. (1981). Baroclinic transport in the Gulf of Alaska, part II. A fresh water driven Coastal Current. Journal of Marine Research, 39, 251-266.

Royer, T. C. (1982). Coastal freshwater discharge in the northeast Pacific. Journal of Geophysical Research, 87, $2017-2021$.

Royer, T. C. (1998). Coastal processes in the Northern North Pacific. In A. R. Robinson, \& K. H. Brink (Eds.), The sea, vol. 11 (pp. 395-414). New York: J. Wiley and Sons.

Schumacher, J. D., Stabeno, P. J., \& Roach, A. T. (1990). Volume transport in the Alaska Coastal Current. Continental Shelf Research, 9, 1071-1083.

Smagorinsky, J. (1963). General circulation experiments with the primitive equations. I. The basic experiment. Monthly Weather Review, 91, 99-164.

Smith, W. H. F., \& Sandwell, D. T. (1997). Global sea floor topography from satellite altimetry and ship depth soundings. Science, 277, 1956-1962.

Song, Y., \& Haidvogel, D. B. (1994). A semi-implicit ocean circulation model using a generalized topography-following coordinate system. Journal of Computational Research, 115, 228-244.

Stabeno, P. J., \& Hermann, A. J. (1996). An eddy resolving model of circulation in the western Gulf of Alaska II. Comparison of results to oceanographic observations. Journal of Geophysical Research, 101, 1151-1161.

Stabeno, P. J., \& Reed, R. K. (1989). Recent observations of variability in the path and vertical structure of the Alaskan Stream. Journal of Physical Oceanography, 19, 1634-1642.

Stabeno, P. J., Reed, R. K., \& Schumacher, J. D. (1995). The Alaskan Coastal Current, continuity of transport and forcing. Journal of Geophysical Research, 100, 2477-2485.

Strub, P. T., \& James, C. (2002a). Altimeter-derived surface circulation in the large-scale NE Pacific gyres: part 1. Annual variability. Progress in Oceanography, 53(2-4), 163-183.

Strub, P. T., \& James, C. (2002b). Altimeter-derived surface circulation in the large-scale NE Pacific gyres: part 2. 1997-1998 El Nino anomalies. Progress in Oceanogaphy, 53(2-4), 185-214.

Swaters, G. E., \& Mysak, L. A. (1985). Topographically-induced baroclinic eddies near a coastline, with application to the Northeast Pacific. Journal of Physical Oceanography, 15, 1470-1485.

Tabata, S. (1982). The anticyclonic, baroclinic eddy off Sitka, Alaska, in the Northeast Pacific Ocean. Journal of Physical Oceanography, 12, 1260-1282. 
Taylor, M., Tribbia, J., \& Iskandarani, M. (1997). The spectral element method for the shallow water equations on the sphere. Journal of Computational Physics, 130, 92.

Thompson, R. E., \& Gower, J. F. R. (1998). A basin-scale oceanic instability event in the Gulf of Alaska. Journal of Geophysical Research, 103, 3033-3040.

US GLOBEC (1996). U.S. GLOBEC Northeast Pacific Implementation Plan. U.S. GLOBEC Report No. 17. University of California, Berkeley, CA. 